\title{
密度和株行距配置对川中丘区夏玉米群体光分布及雌雄穗分化的影响
}

\author{
金 容 ${ }^{1,2}$ 李 钟 $^{2}$ 杨 云 $^{2}$ 周 芳 ${ }^{1}$ 杜伦静 $^{1}$ 李小龙 $^{1}$ 孔凡磊 $^{1}$ \\ 袁继超 ${ }^{1, *}$
}

${ }^{1}$ 四川农业大学农学院 / 作物生理生态及栽培四川省重点实验室, 四川成都 $611130 ;{ }^{2}$ 南充市农业科学院, 四川南充 637000

摘 要: 为了便于全程机械化生产, 四川中部部分地区玉米生产已逐渐由套作春播转变为净作夏播。为了明确本区 域净作夏玉米高产、宜机的群体结构, 采用两因素裂区试验设计, 研究了种植密度和株行距配置对夏玉米群体光分布 及雌雄穗分化和产量的影响。结果表明, 随种植密度增加, 玉米有效穗数增加, 但因空秆和倒伏增加导致有效穗数增 幅逐渐减少甚至最终降低; 密度增加使玉米叶片茎叶夹角和开张角降低, 叶向值增加, 群体透光率明显降低, 消光 系数增大, 雌雄穗小穗分化期和小花分化期幼穗长度和中部直径、吐丝期雄穗主轴长度和成对小穗数以及雌穗总小 花数、吐丝小花数、受精小花数和单株果穗受精率均降低, 而退化小花数、败育花数和花败育率均增加, 最终导致玉 米秃尖变长, 穗粒数和百粒重显著降低。产量随种植密度增加而先增后降, 以 67,500 株 $\mathrm{hm}^{-2}$ 最高, 2 年平均较 45,000 株 $\mathrm{hm}^{-2}$ 和 90,000 株 $\mathrm{hm}^{-2}$ 密度分别显著增加 $17.00 \%$ 和 $14.03 \%$ 。此外, 2 年在 45,000 株 $\mathrm{hm}^{-2}$ 和 67,500 株 $\mathrm{hm}$ 密度 下, 等行距均优于相应宽窄行, $60 \mathrm{~cm}$ 等行距处理下玉米株型紧凑, 能改善群体受光条件, 提高玉米单株果穗受精率, 降低小花败育率, 籽粒产量较高; 在 2018 年 90,000 株 $\mathrm{hm}^{-2}$ 密度下, $(110+50) \mathrm{cm}$ 宽窄行处理更能改善田间通风透光 条件, 促进雌雄穗分化, 提高玉米籽粒产量。因此, 川中丘区夏玉米高产栽培应适当缩行增密, 宜采用 67,500 株 $\mathrm{hm}^{-2}$ 密度搭配 $60 \mathrm{~cm}$ 等行距种植。

关键词: 密度; 株行距配置; 玉米; 叶型; 光合有效辐射; 雌雄穗; 产量构成

\section{Effects of density and row spacing on population light distribution and male and female spike differentiation of summer maize in hilly area of central Si- chuan}

JIN Rong ${ }^{1,2}$, LI Zhong ${ }^{2}$, YANG Yun ${ }^{2}$, ZHOU Fang ${ }^{1}$, DU Lun-Jing ${ }^{1}$, LI Xiao-Long ${ }^{1}$, KONG Fan-Lei ${ }^{1}$, and YUAN Ji-Chao ${ }^{1, *}$

${ }^{1}$ College Agronomy of Sichuan Agricultural University / Key Laboratory of Crop Physiology and Ecology and Cultivation of Sichuan Province, Chengdu 611130, Sichuan, China; ${ }^{2}$ Nanchong Academy of Agricultural Sciences, Nanchong 637000, Sichuan, China

\begin{abstract}
In order to facilitate mechanical production, the corn production in parts of central Sichuan has gradually changed from the intercropping spring planting to the net summer planting. In order to clarify the population structure of the net summer maize for high yield and suitable for mechanization in the region, the effects of density and row spacing on population light distribution and male and female spike differentiation of summer maize were studied with two-factor splitting test design. With the increase of planting density, the maize effective panicle increased, with a gradually decreased increase range, and finally decreased due to the increase of empty stalk and lodging. With the density increased, the angle between stem and leaf and the opening angle decreased, the leaf orientation value increased, the group transmittance decreased significantly, the extinction coefficient increased, and the
\end{abstract}

\footnotetext{
本研究由国家公益性行业(农业)科研专项经费(20150312705), 国家重点研发计划项目(玉米密植机收)(2016YFD0300307)和国家重点 研发计划项目(资源高效模式)(2016YFD0300209)资助。

This study was supported by the Special Fund for Agro-scientific Research in the Public Interest (20150312705), the National Key Research and Developing Program of China (Dense Planting and Machine Harvesting) (2016YFD0300307), and the National Key Research and Developing Program (China-Resource Efficient Mode) (2016YFD0300209).

*通信作者(Corresponding author): 袁继超, E-mail: yuanjichao5@163.com

第一作者联系方式: E-mail: 1256100416@qq.com
}

Received (收稿日期): 2019-06-12; Accepted (接受日期): 2019-09-26; Published online (网络出版日期): 2019-10-14.

URL: http://kns.cnki.net/kcms/detail/11.1809.S.20191014.1343.006.html 
spike length and middle diameter of the male and female spikes at the panicle differentiation and floret differentiation stages, the tassel spindle length and pairs spikelet number at the silking stage, as well as the total small flower number, the silking floret number, the fertilized floret number and the fertilization rate per plant decreased, while the degraded floret number, the abortive flower number and the abortion rate increased, which eventually led maize bald ear tip become longer, the grain number per panicle and 100-grain weight decreased significantly. With the increase of planting density, the yield increased first and then decreased, with the highest yield under 67,500 plants $\mathrm{hm}^{-2}$. For the average yield of two years, the treatment of $67,500 \mathrm{plants}^{-2} \mathrm{hm}^{-2} \mathrm{a}$ significant increase of $17.00 \%$ and $14.03 \%$ compared with the treatments of 45,000 and 90,000 plants hm ${ }^{-2}$, respectively. In addition, under the density of 45,000 and 67,500 plants $\mathrm{hm}^{-2}$ for two years, the equal row spacing was better than the corresponding wide and narrow rows, and the maize plant type was compact in $60 \mathrm{~cm}$ row spacing treatment, which improved group light conditions and fertilization rate per plant, reduced small flower abortion rate, and increased maize yield. Under the density of 90,000 plants $\mathrm{hm}^{-2}$ in 2018, $(110+50) \mathrm{cm}$ wide and narrow treatment improved the ventilation and light transmission conditions in the field, promoted the differentiation of female and male ears, and increased the maize yield. Therefore, the high-yield cultivation of summer maize in the central Sichuan area should be performed by properly reducing row spacing and increasing plant density, which are suggested as $(60+60) \mathrm{cm}$ and 67,500 plants $\mathrm{hm}^{-2}$ respectively.

Keywords: density; row spacing; maize; leaf type; photosynthetically active radiation; male and female spike; yield composition

玉米(Zea mays L.)产量是由单位面积穗数、穗粒 数和千粒重三要素构成, 适当增密是提高玉米有效 穗数的重要措施 ${ }^{[1]}$, 但随着种植密度增加, 冠层内 通风透光不良, 削弱了中下部叶片的光照条件 ${ }^{[2]}$, 导致玉米雌雄穗发育得不到充足的光合产物 ${ }^{[3]}$, 而 合理的株行距配置可以使光能在玉米群体冠层内的 分布更加合理, 充分利用不同层次的光资源 ${ }^{[4]}$, 对 促进玉米穗部发育及产量的提高具有重要意义, 而

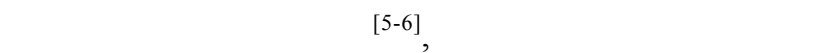
的必由之路。前人对玉米穗分化与叶龄指数以及植 株外部形态的关系研究较多 ${ }^{[7-12]}$, 关于密度对玉米 雌雄穗分化的影响也有一些报道 ${ }^{[13]}$, 但鲜见株行距 配置在这方面的研究, 尤其是西南地区株行距配置 对玉米群体内光分布和雌雄穗分化及其与密度的互 作效应方面。川中丘区是西南玉米主产区之一, 过
去以套作春播为主, 为适应机械化生产, 近年在一 些地区逐渐转变为净作夏播, 为了探明其适宜群体 结构, 本文设置了不同密度和株行距配置的田间试 验, 研究其对玉米株叶型及群体光能分布、雌雄穗 分化特性及产量构成的影响, 以期为川中丘区净作 夏玉米的高产栽培和机械化收获提供理论依据。

\section{1 材料与方法}

\section{1 试验地概况}

四川省德阳市中江县新建村 $\left(30^{\circ} 95^{\prime} \mathrm{N}, 104^{\circ} 63^{\prime} \mathrm{E}\right)$ 地属亚热带季风气候, 无霜期 $286 \mathrm{~d}$, 玉米生育期间 气温和降水量见图 1。试验田土壤质地为紫色壤土, 耕层 0 20 cm 含有机质 $21.03 \mathrm{~g} \mathrm{~kg}^{-1}$ 、全氮 $1.39 \mathrm{~g}$ $\mathrm{kg}^{-1}$ 、碱解氮 $21.96 \mathrm{mg} \mathrm{kg}^{-1}$ 、速效磷 $5.83 \mathrm{mg} \mathrm{kg}^{-1}$ 、 速效钾 $112.68 \mathrm{mg} \mathrm{kg}^{-1}, \mathrm{pH} 7.60$ 。

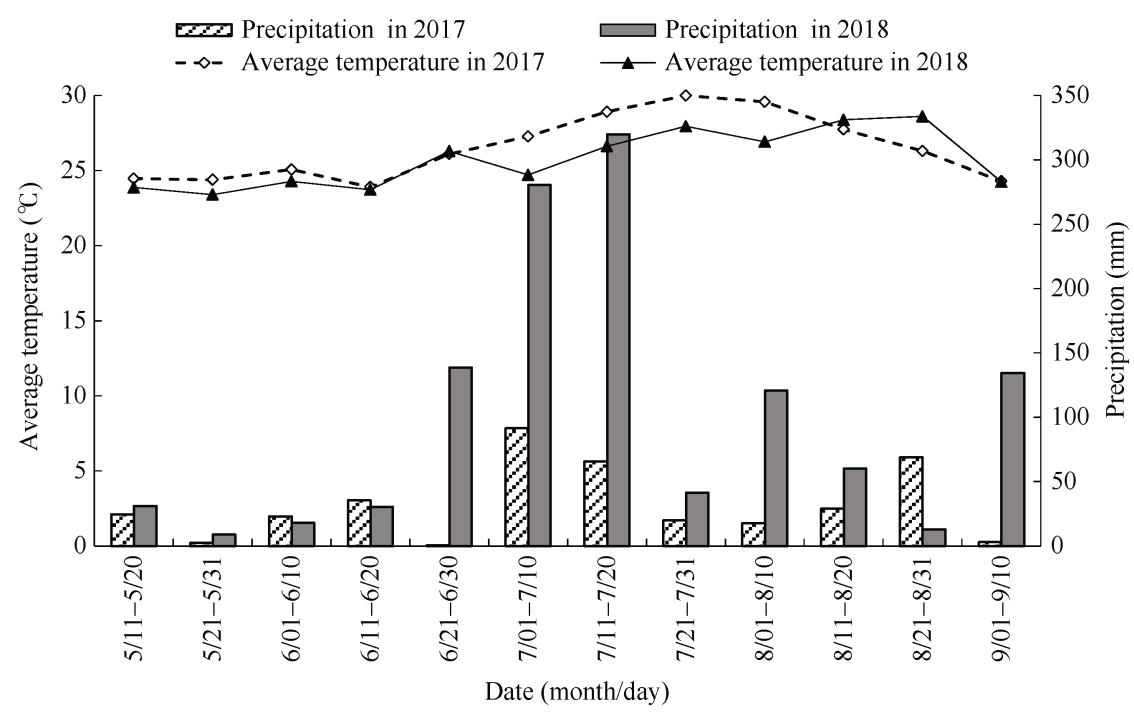

图 1 玉米生育期间气温和降水量

Fig. 1 Average temperature and rainfall of the experiment site during the growing period of maize 


\section{2 试验设计}

供试玉米品种为当前生产上大面积应用的半紧 凑型玉米杂交种正红 6 号, 由四川农大正红生物技 术有限责任公司提供。采用两因素裂区试验设计, 种植密度为主区, 株行距配置为副区, 重复 3 次。 2017 年设 2 个种植密度, 即 45,000 株 $\mathrm{hm}^{-2}$ (A1)和 67,500 株 $\mathrm{hm}^{-2}$ (A2); 5 种行距配置 $(\mathrm{cm}+\mathrm{cm})$, 即 $60+60$ (B1)、80+40(B2)、80+80(B3)、110+50(B4)和 $100+100(B 5) 。 2018$ 年设 3 个种植密度, 即 45,000 株 $\mathrm{hm}^{-2}(\mathrm{~A} 1) 、 67,500$ 株 $\mathrm{hm}^{-2}(\mathrm{~A} 2)$ 和 90,000株 $\mathrm{hm}^{-2}$ (A3)； 4 种行距配置 $(\mathrm{cm}+\mathrm{cm})$, 即 $60+60(\mathrm{~B} 1)$ 、 $80+40$ (B2)、80+80(B3)和 $110+50(\mathrm{~B} 4)$ 。2 017 年于 5 月 16 日播种, 9 月 3 日收获，平均小区面积为 27.36 $\mathrm{m}^{2}, 2018$ 年于 5 月 15 日播种, 9 月 5 日收获, 平均小 区面积为 $23.10 \mathrm{~m}^{2}, 2$ 年均为 6 行区, 单株留苗。底 施复合肥 $\left(\mathrm{N}: \mathrm{P}_{2} \mathrm{O}_{5}: \mathrm{K}_{2} \mathrm{O}=15: 6: 8\right) 750 \mathrm{~kg} \mathrm{hm}^{-2}$; 大喇叭口期攻穗肥追施尿素(含氮量 $\geq 46 \%$ ) 112.50 $\mathrm{kg} \mathrm{hm}^{-2}$ 。其他栽培管理措施按当地高产要求进行。

\section{3 测定项目及方法}

\subsection{1 叶型选取吐丝期每小区有代表性植株连} 续 10 株, 在田间用米尺测定穗三叶的叶长和叶基至 叶片最高点的距离, 用量角器测定茎叶夹角 (即叶脉 与茎秆向上方向的夹角) 和开张角 (即自然状态下叶 枕至叶尖的连线与茎秆的夹角 $)^{[14]}$, 并计算叶向值 (LOV)。

$$
\mathrm{LOV}=\frac{\sum_{i=1}^{n}\left(90^{\circ}-\theta\right)\left(L_{\mathrm{s}} / L_{\mathrm{t}}\right)}{n}
$$

式中, $\theta$ 为茎叶夹角; $L_{\mathrm{t}}$ 为叶片长度; $L_{\mathrm{s}}$ 为叶基到最 高点距离; $n$ 为测定叶片数。

\subsection{2 群体光分布 于吐丝期选择晴朗无云天气,}

用 LI-1400 光量子仪在行间以对角线方式, 按离地 面 0、50、100、150、200、250 cm 处分层测定冠层 内部的光合有效辐射量 ( $I$, 按宽行和窄行分别测定) 和冠层顶部入射光合有效辐射量 $\left(I_{0}\right)$, 计算冠层光合 有效辐射透过率 $\left(\mathrm{PAR}\right.$ 透过率 $\left.=I / I_{0}\right)$ 。

\subsection{3 雌雄穗分化进程从 5 片展开叶开始观察} 雄穗的幼穗分化, 一直到抽雄期, 从 8 片展开叶开 始观察雌穗穗分化, 直到吐丝期结束, 每 $3 \mathrm{~d}$ 观察一 次。用解剖针剥取生长雉, 放入 FAA 固定液, $4^{\circ} \mathrm{C}$ 保 存, 统一用 OLYMPUS 体视显微镜观察、拍照和测 量长度。

\subsection{4 雌雄穗分化特性}

雌穗小花抽丝 7 10 d
(吐丝达到最大)后, 选取每处理 5 株生长正常的典型 植株, 测定每株雄穗主轴长度、分枝数、成对小穗 数, 借助铌子在解剖镜下观察每雌穗的小花总数(生 长锥上所有分化的小花)、吐丝小花数(花丝伸长的所 有小花即花丝数)、受精小花数(受精后枯萎的所有小 花: 以花丝基部变褐、萎蒸从子房脱落为准)。

未受精小花数 $=$ 吐丝小花数 - 受精小花数

退化小花数 $=$ 总小花数 - 吐丝小花数

小花败育数 $=$ 退化小花数 + 未受精花数

单株果穗受精率 = 受精小花数/小花总数 $\times$ $100 \%$

小花败育率 $=$ 小花败育数/小花总数 $\times 100 \%$

1.3.5 产量及其构成因素收获前统计各小区有 效穗数、空秆率、双穗率、倒伏率和倒折率并实收 计产, 收获后采用平均穗重法从各小区选取 20 个代 表性果穗考种, 考察穗长、穗粗、秃尖长、穗行数、 行粒数、籽粒总重、百粒重以及含水率等。

\section{4 数据统计与分析}

采用 Microsoft Excel 2010 和 Graph Pad Prism 5.0 软件进行数据处理和作图, DPS 7.05 软件进行统 计分析, LSD 法进行多重比较, 图表中数据为平均 值土标准误。

\section{2 结果与分析}

\section{1 密度和株行距配置对玉米叶型的影响}

从图 2 可以看出, 随叶位上升, 叶片叶向值呈 下降趋势, 茎叶夹角呈先增后降趋势, 而开张角则 呈增加趋势。随种植密度增加, 叶向值增大, 茎叶夹 角和开张角变小, 2017 年 $\mathrm{A} 2$ 密度较 $\mathrm{A} 1$ 密度穗三叶 平均叶向值增加 $10.50 \%$, 茎叶夹角和平均开张角分 别减小 $10.39 \%$ 和 $5.54 \% ; 2018$ 年 A3 密度较 A1、A2 密度穗三叶平均叶向值分别增加 $13.53 \% 、 6.96 \%$, 茎 叶夹角和平均开张角分别减小 $17.49 \%$ 、 $5.59 \%$ 和 $26.37 \% 、 23.02 \%$ ，说明密度增加后植株能在一定程 度上自动调节叶片着生角度, 株型变紧凑。同一密 度下, 平均行距增大, 穗三叶茎叶夹角和开张角均 增加(2017 年 A1B4 穗上叶和 2018 年 A1B4 穗位叶 开张角减小), 叶向值均减小, 说明行距的增大使叶 片生长空间相对加大, 变得较为舒展。等行距处理 较相应宽窄行处理, 总体来说穗三叶叶向值呈降低 趋势, 茎叶夹角和开张角呈增加趋势, 但在 A1 和 A2 密度下穗位叶的叶向值和开张角处理间差异不 显著。 


\section{2 密度和株行距配置对群体内透光率和消光} 系数的影响

随测定高度的增加, 玉米群体内的透光率逐渐 增大(图 3)。密度增加, 群体内透光率降低, 尽管密 度增加植株能在一定程度上通过调节叶片生长角度 来改善透光率, 但其调节程度远不及密度增加对透 光率的影响, 因此密度增加群体内透光率仍呈现明 显降低的趋势, 尤其是中部透光率。2017 年 A2 密
度各层次平均透光率较 A1 密度减少 $22.49 \% ; 2018$ 年 $\mathrm{A} 3$ 密度平均透光率较 $\mathrm{A} 1$ 、A2 密度分别减少 $40.38 \%$ 和 $21.93 \%$ 。同一密度下，平均行距增大，群 体内透光率均增加, 均在 B4-宽行处理下有最大透 光率，其次为 B5-等行距处理。宽窄行处理中宽行和 窄行的透光率差异较大, 表现为宽行 $>$ 相应等行 $>$ 窄 行。2017 年整体透光率高于 2018 年, 主要是因为 2018 年光照整体较弱。
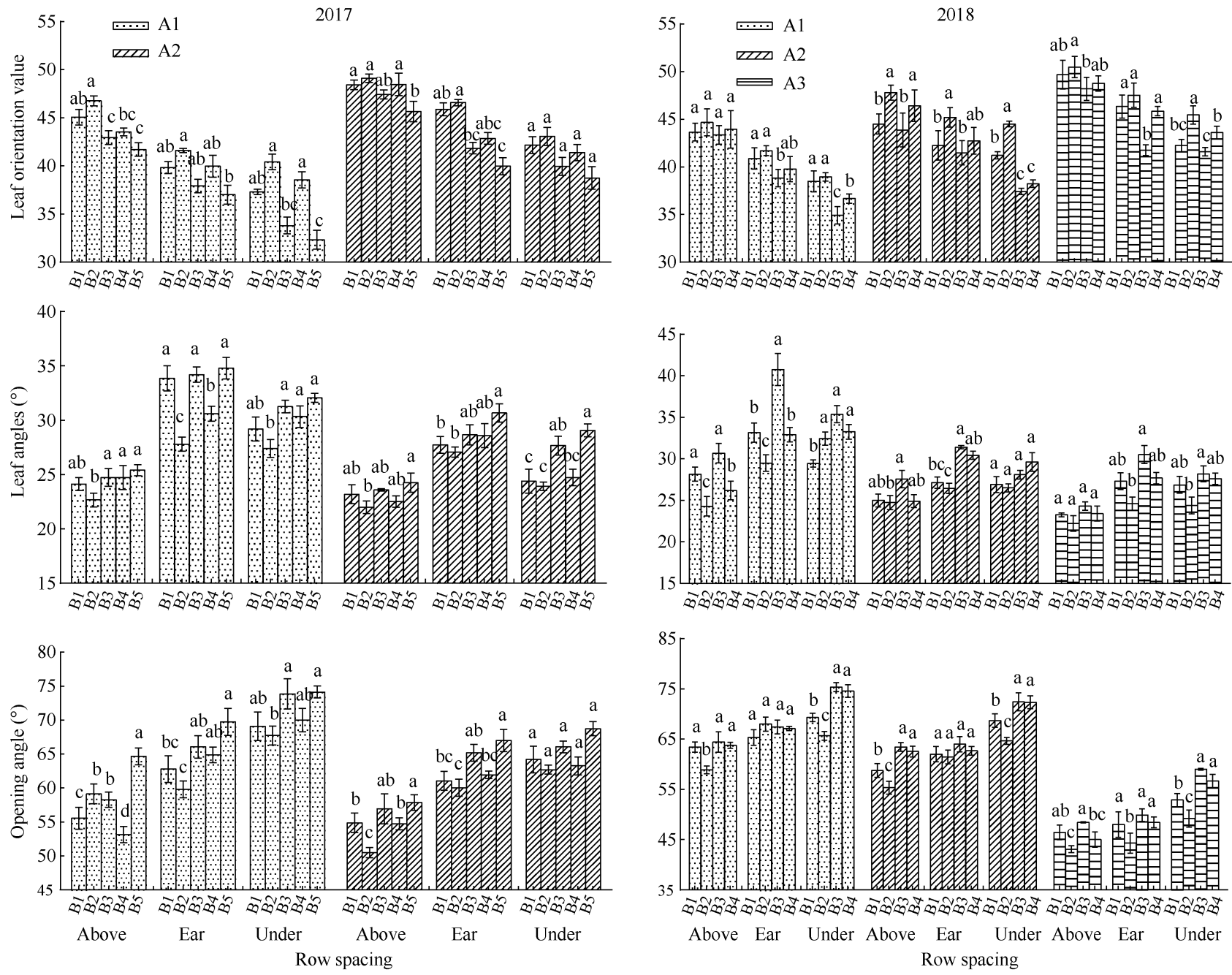

图 2 密度和株行距配置对玉米叶片着生状态的影响

Fig. 2 Effects of density and row spacing on the growth status of maize leaves

柱上不同小写字母表示处理间差异显著 $(P<0.05) ; \mathrm{A} 1 、 \mathrm{~A} 2$ 和 A3 代表种植密度分别为 $45,000 、 67,500$ 和 90,000 株 $\mathrm{hm}{ }^{-2} ; \mathrm{B} 1$ 、B2、B3、 B4 和 B5 代表行距配置分别为 $(60+60) 、(80+40) 、(80+80) 、(110+50)$ 和 $(100+100) \mathrm{cm} ; A b o v e 、$ Ear 和 Under 分别代表穗上第 1 叶、穗 位叶和穗下第 1 叶。

Different lowercase letters above the column indicate significant difference at the 0.05 probability level among treatments; A1, A2, and A3 represent planting densities of 45,000, 67,500, and 90,000 plants $\mathrm{hm}^{-2}$, respectively; B1, B2, B3, B4, and B5 represent row spacings of $(60+60),(80+40),(80+80),(110+50)$, and $(100+100) \mathrm{cm}$, respectively; Above, ear, and under represent $1 \mathrm{st}$ leaf above the ear, ear leaf, and $1 \mathrm{st}$ leaf under the ear, respectively. 

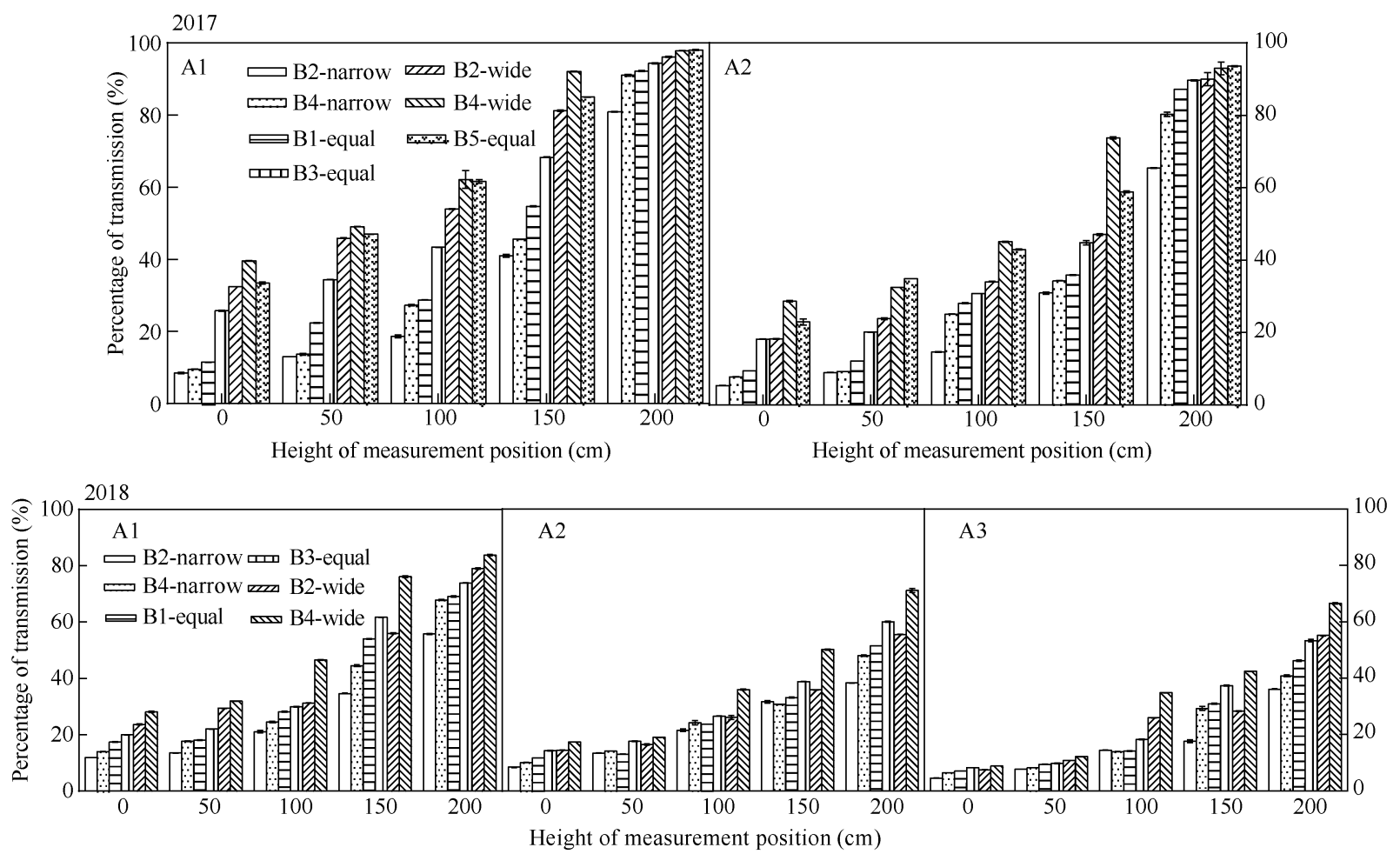

图 3 密度和株行距配置对玉米群体透光率的影响

Fig. 3 Effects of density and row spacing on maize population light transmittance

A1、A2 和 A3 代表种植密度分别为 45,000、67,500 和 90,000 株 $\mathrm{hm}^{-2}$; B2-narrow、B4-narrow、B1-equal、B3-equal、B2-wide、B4-wide 和 B5-equal 分别代表 40、50、60、80、80、110 和 $100 \mathrm{~cm}$ 的行距。

A1, A2, and A3 represent planting densities of 45,000, 67,500, and 90,000 plants $\mathrm{hm}^{-2}$, respectively; B2-narrow, B4-narrow, B1-equal, B3-equal, B2-wide, B4-wide, and B5-equal represent row spacings of 40,50,60, 80, 80, 110, and $100 \mathrm{~cm}$, respectively.

消光系数 $(K)$ 反映群体冠层光照强度的衰减程 度, $K$ 值越大, 光照衰减越多, 下部叶片受光越少 ${ }^{[15]}$ 。 由表 1 可知, 消光系数与群体内透光率表现相反, 密度增加, 玉米冠层消光系数变大, 2017 年 A2 密度 平均消光系数较 A1 密度增加 $22.86 \%, 2018$ 年 A3 密 度较 A2 和 A1 密度分别增加 $46.58 \%$ 和 $28.92 \%$ 。同 一密度下, 平均行距增大，等行距和宽窄行处理消 光系数均减小, 且窄行 $>$ 相应等行距 $>$ 宽行。2017 年 窄行平均消光系数较相应等行距和宽行分别大 $39.60 \%$ 和 $136.36 \%$ (A1)、30.73\%和 $81.40 \%$ (A2); 2018 年窄行平均消光系数较相应等行距和宽行分别 大 $15.54 \%$ 和 $46.15 \%$ (A1)、7.83\%和 $15.48 \%$ (A2)、 $6.60 \%$ 和 $11.88 \%(\mathrm{~A} 3)$ 。

回归分析表明, 消光系数 $K$ 与种植密度 $\left(X_{1}\right.$, 株 $\left.\mathrm{hm}^{-2}\right)$ 和行距 $\left(X_{2}, \mathrm{~cm}\right)$ 呈极显著线性相关, 回归方程 为 $K=0.0083+7.29 \times 10^{-8} X_{1}-62.5 \times 10^{-5} X_{2} \quad\left(R^{2}=\right.$ $0.7871^{* *}, n=32$ ), 在相同行距下, 密度每增加
10,000 株 $\mathrm{hm}^{-2}, K$ 增加 0.000729 ; 在相同密度下, 行 距每增加 $10 \mathrm{~cm}, K$ 值降低 0.00063 。

\section{3 密度和株行距配置对玉米幼穗分化的影响}

2.3.1 对分化进程和形态的影响 由表 2、图 4 和图 5 可知, 在不同种植密度和株行距配置下, 各 处理玉米雌穗和雄穗进入小穗分化期和小花分化期 的进度差异不显著, 但雄性幼穗进入小穗分化期较 雌性幼穗早 $9 \mathrm{~d}$ 左右。密度增加, 玉米雌雄穗幼穗长 度和中部直径均降低, 由 $\mathrm{A} 1$ 密度增加到 $\mathrm{A} 2$ 密度时, 2 个时期平均, 雌穗幼穗长度和中部直径分别降低 $25.23 \%$ 和 $4.32 \%$, 雄穗幼穗则分别降低 $15.86 \%$ 和 $14.00 \%$ 。不同的株行距配置对玉米雌雄穗幼穗小穗 分化期的长度和中部直径影响较小, 但对小花分化 期幼穗的大小影响较大, 尤其是幼穗长度, 平均行 距增加, 雌雄穗幼穗长度总体呈降低趋势, 等行距 处理幼穗长度均大于相应宽窄行处理(雄穗 $\mathrm{A} 1 \mathrm{~B} 3$ 处 理除外)。 
表 1 不同密度和行距配置下玉米群体消光系数方程 $\left[\left(\ln \left(I / I_{0}\right)=\boldsymbol{k h}+\boldsymbol{a}\right)\right]$

Table 1 Extinction coefficient equation $\left[\left(\ln \left(I / I_{0}\right)=k h+a\right)\right]$ of corn population under different densities and configurations

\begin{tabular}{|c|c|c|c|c|}
\hline $\begin{array}{l}\text { 年份 } \\
\text { Year }\end{array}$ & $\begin{array}{c}\text { 密度 } \\
\text { Density }\end{array}$ & $\begin{array}{c}\text { 行距 } \\
\text { Row spacing }\end{array}$ & $\begin{array}{c}\text { 消光系数方程 } \\
\text { Logarithmic function }\end{array}$ & $R^{2}$ \\
\hline \multirow[t]{14}{*}{2017} & A1 & B1-等 B1-equal & $\ln \left(I / I_{0}\right)=0.0090 h+2.5523$ & $0.9696^{* *}$ \\
\hline & & B2-宽 B2-wide & $\ln \left(I / I_{0}\right)=0.0047 h+3.5541$ & $0.9531^{* *}$ \\
\hline & & B2-窄 B2-narrow & $\ln \left(I / I_{0}\right)=0.0106 h+2.0671$ & $0.9791^{* *}$ \\
\hline & & B3-等 B3-equal & $\ln \left(I / I_{0}\right)=0.0059 h+3.2565$ & $0.9735^{* *}$ \\
\hline & & B4-宽 B4-wide & $\ln \left(I / I_{0}\right)=0.0041 h+3.7290$ & $0.9239^{* *}$ \\
\hline & & B4-窄 B4-narrow & $\ln \left(I / I_{0}\right)=0.0102 h+2.2405$ & $0.9767^{* *}$ \\
\hline & & B5-等 B5-equal & $\ln \left(I / I_{0}\right)=0.0046 h+3.6143$ & $0.9384^{* *}$ \\
\hline & A2 & B1-等 B1-equal & $\ln \left(I / I_{0}\right)=0.0103 h+2.1728$ & $0.9674^{* *}$ \\
\hline & & B2-宽 B2-wide & $\ln \left(I / I_{0}\right)=0.0073 h+2.8467$ & $0.9763^{* *}$ \\
\hline & & B2-窄 B2-narrow & $\ln \left(I / I_{0}\right)=0.0122 h+1.6108$ & $0.9926^{* *}$ \\
\hline & & B3-等 B3-equal & $\ln \left(I / I_{0}\right)=0.0076 h+2.7509$ & $0.9598^{* *}$ \\
\hline & & B4-宽 B4-wide & $\ln \left(I / I_{0}\right)=0.0056 h+3.3087$ & $0.9575^{* *}$ \\
\hline & & B4-窄 B4-narrow & $\ln \left(I / I_{0}\right)=0.0112 h+1.9446$ & $0.9674^{* *}$ \\
\hline & & B5-等 B5-equal & $\ln \left(I / I_{0}\right)=0.0061 h+3.1839$ & $0.9775^{* *}$ \\
\hline \multirow[t]{18}{*}{2018} & A1 & B1-等 B1-equal & $\ln \left(I / I_{0}\right)=0.0077 h+2.6975$ & $0.9640^{* *}$ \\
\hline & & B2-宽 B2-wide & $\ln \left(I / I_{0}\right)=0.0061 h+3.0639$ & $0.9576^{* *}$ \\
\hline & & B2-窄 B2-narrow & $\ln \left(I / I_{0}\right)=0.0088 h+2.2892$ & $0.9760^{* *}$ \\
\hline & & B3-等 B3-equal & $\ln \left(I / I_{0}\right)=0.0071 h+2.8679$ & $0.9554^{* *}$ \\
\hline & & B4-宽 B4-wide & $\ln \left(I / I_{0}\right)=0.0056 h+3.3071$ & $0.9567^{* *}$ \\
\hline & & B4-窄 B4-narrow & $\ln \left(I / I_{0}\right)=0.0083 h+2.5240$ & $0.9855^{* *}$ \\
\hline & A2 & B1-等 B1-equal & $\ln \left(I / I_{0}\right)=0.0087 h+2.2735$ & $0.9735^{* *}$ \\
\hline & & B2-宽 B2-wide & $\ln \left(I / I_{0}\right)=0.0078 h+2.5173$ & $0.9739^{* *}$ \\
\hline & & B2-窄 B2-narrow & $\ln \left(I / I_{0}\right)=0.0091 h+2.1131$ & $0.9645^{* *}$ \\
\hline & & B3-等 B3-equal & $\ln \left(I / I_{0}\right)=0.0079 h+2.5433$ & $0.9878^{* *}$ \\
\hline & & B4-宽 B4-wide & $\ln \left(I / I_{0}\right)=0.0077 h+2.8264$ & $0.9424^{* *}$ \\
\hline & & B4-窄 B4-narrow & $\ln \left(I / I_{0}\right)=0.0088 h+2.2422$ & $0.9789^{* *}$ \\
\hline & A 3 & B1-等 B1-equal & $\ln \left(I / I_{0}\right)=0.0108 h+1.7759$ & $0.9797^{* *}$ \\
\hline & & B2-宽 B2-wide & $\ln \left(I / I_{0}\right)=0.0102 h+1.9959$ & $0.9763^{* *}$ \\
\hline & & B2-窄 B2-narrow & $\ln \left(I / I_{0}\right)=0.0116 h+1.4354$ & $0.9661^{* *}$ \\
\hline & & B3-等 B3-equal & $\ln \left(I / I_{0}\right)=0.0104 h+1.9499$ & $0.9817^{* *}$ \\
\hline & & B4-宽 B4-wide & $\ln \left(I / I_{0}\right)=0.0100 h+2.2203$ & $0.9614^{* *}$ \\
\hline & & B4-窄 B4-narrow & $\ln \left(I / I_{0}\right)=0.0110 h+1.6780$ & $0.9755^{* *}$ \\
\hline
\end{tabular}

"”表示在 0.01 水平上差异显著; A1、A2 和 A3 代表种植密度分别为 $45,000 、 67,500$ 和 90,000 株 $^{\mathrm{h}} \mathrm{hm}^{-2} ; \mathrm{B} 1$-等、B2-宽、B2-窄、B3-等、 B4-宽、B4-窄和 B5-等分别代表 $60 、 80 、 40 、 80 、 110 、 50$ 和 $100 \mathrm{~cm}$ 的行距; $I$ 和 $I_{0}$ 分别代表冠层内部的光合有效辐射量和冠层顶部 入射光合有效辐射量; $h$ 为测定高度; $k$ 为方程中的斜率值即消光系数; $a$ 为常数。

"** represents significantly different at the 0.01 probability level; A1, A2, and A3 represent the densities of 45,000, 67,500, and 90,000 plants $\mathrm{hm}^{-2}$, respectively; B1-equal, B2-wide, B2-narrow, B3-equal, B4-wide, B4-narrow, and B5-equal represent the row spacings of 60, 80, 40, 80, 110,50 , and $100 \mathrm{~cm}$, respectively. $I$ and $I_{0}$ represent the photosynthetically active radiation amount inside the canopy and the incident photosynthetically active radiation amount at the top of the canopy respectively; $h$ is the measured height; $k$ is the slope value in the equation, that is, the extinction coefficient; $a$ is a constant. 
表 2 密度和株行距配置对玉米雌雄穗幼穗分化的影响

Table 2 Effects of density and row spacing on ear and tassel spikelet differentiation of maize

\begin{tabular}{|c|c|c|c|c|c|c|}
\hline \multirow[b]{2}{*}{$\begin{array}{l}\text { 时期 } \\
\text { Stage }\end{array}$} & \multirow[b]{2}{*}{$\begin{array}{c}\text { 密度 } \\
\text { Density }\end{array}$} & \multirow[b]{2}{*}{$\begin{array}{l}\text { 株行距配置 } \\
\text { Row spacing }\end{array}$} & \multicolumn{2}{|c|}{ 雌穗 Ear } & \multicolumn{2}{|c|}{ 雄穗 Tassel } \\
\hline & & & $\begin{array}{c}\text { 长度 } \\
\text { Length } \\
(\mathrm{mm})\end{array}$ & $\begin{array}{c}\text { 中部直径 } \\
\text { Middle part } \\
\text { diameter }(\mathrm{mm}) \\
\end{array}$ & $\begin{array}{c}\text { 长度 } \\
\text { Length } \\
(\mathrm{mm}) \\
\end{array}$ & $\begin{array}{c}\text { 中部直径 } \\
\text { Middle part diameter } \\
(\mathrm{mm})\end{array}$ \\
\hline 小穗分化期 & A1 & $\mathrm{B} 1$ & 6.59 & 1.66 & 5.73 & 1.43 \\
\hline \multirow[t]{11}{*}{ Spikelet differentiation period } & & B2 & 5.61 & 1.55 & 5.68 & 1.06 \\
\hline & & B3 & 6.26 & 1.75 & 5.46 & 1.32 \\
\hline & & B4 & 5.32 & 1.98 & 4.84 & 0.96 \\
\hline & & B5 & 5.66 & 1.41 & 4.56 & 1.05 \\
\hline & & 平均值 Average & 5.89 & 1.67 & 5.25 & 1.16 \\
\hline & $\mathrm{A} 2$ & $\mathrm{~B} 1$ & 5.41 & 1.69 & 4.93 & 1.18 \\
\hline & & $\mathrm{B} 2$ & 5.11 & 1.46 & 4.85 & 1.06 \\
\hline & & B3 & 5.00 & 1.59 & 3.46 & 0.96 \\
\hline & & B4 & 4.56 & 1.57 & 3.32 & 0.97 \\
\hline & & B5 & 4.21 & 1.57 & 3.13 & 0.93 \\
\hline & & 平均值 Average & 4.86 & 1.58 & 3.94 & 1.02 \\
\hline 小花分化期 & A1 & B1 & 24.63 & 4.11 & 22.58 & 4.36 \\
\hline \multirow[t]{11}{*}{ Floret differentiation period } & & B2 & 21.08 & 4.13 & 21.88 & 3.72 \\
\hline & & B3 & 22.20 & 4.26 & 20.32 & 3.98 \\
\hline & & B4 & 19.95 & 4.30 & 20.39 & 3.98 \\
\hline & & B5 & 20.01 & 4.03 & 20.46 & 3.49 \\
\hline & & 平均值 Average & 21.57 & 4.17 & 21.13 & 3.91 \\
\hline & $\mathrm{A} 2$ & B1 & 18.28 & 3.83 & 21.37 & 3.95 \\
\hline & & B2 & 17.74 & 4.13 & 17.69 & 3.15 \\
\hline & & B3 & 14.49 & 4.11 & 17.93 & 3.49 \\
\hline & & B4 & 14.43 & 4.08 & 17.18 & 3.02 \\
\hline & & B5 & 13.44 & 3.89 & 17.12 & 3.09 \\
\hline & & 平均值 Average & 15.68 & 4.01 & 18.26 & 3.34 \\
\hline
\end{tabular}

A1、A2 和 A3 代表种植密度分别为 $45,000 、 67,500$ 和 90,000 株 $\mathrm{hm}^{-2} ; \mathrm{B} 1 、 \mathrm{~B} 2 、 \mathrm{~B} 3 、 \mathrm{~B} 4$ 和 B5 代表株行距配置分别为(60+60)、(80+40)、 $(80+80) 、(110+50)$ 和 $(100+100) \mathrm{cm}$ 。

$\mathrm{A} 1, \mathrm{~A} 2$, and $\mathrm{A} 3$ represent the densities of $45,000,67,500$, and 90,000 plants $\mathrm{hm}^{-2}$, respectively; B1, B2, B3, B4, and B5 represent the row spacings of $(60+60),(80+40),(80+80),(110+50)$, and $(100+100) \mathrm{cm}$, respectively.
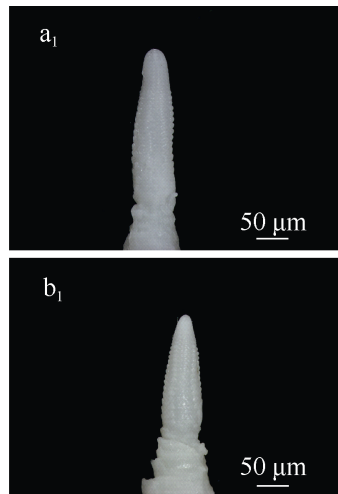
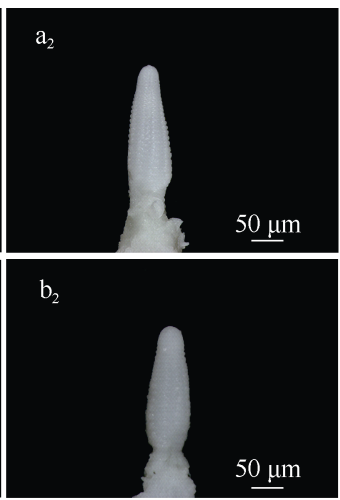
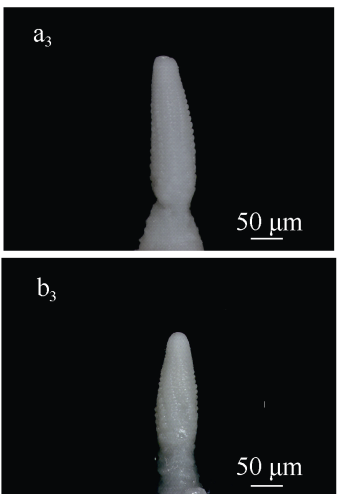
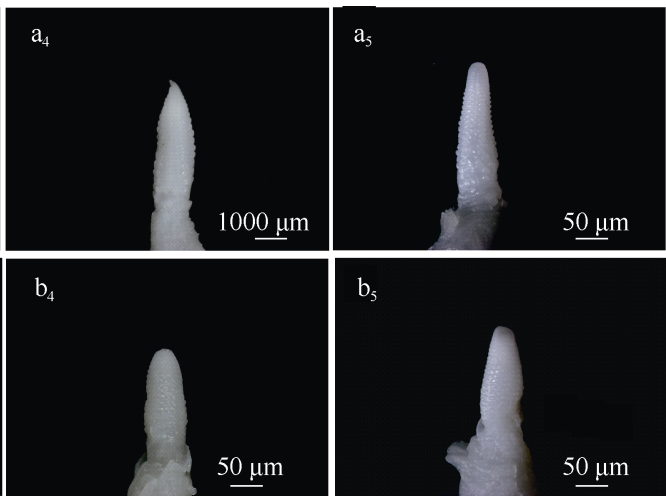

(图 4) 

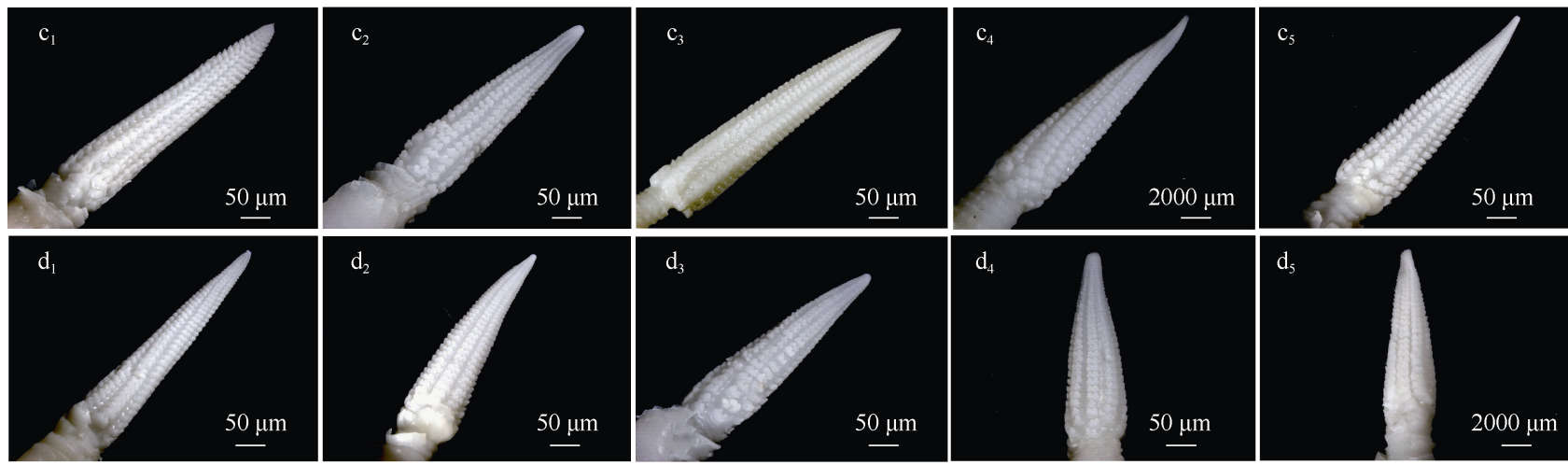

图 4 玉米雌穗小穗分化和小花分化期形态特征

Fig. 4 Morphological characteristics in spikelet differentiation and floret differentiation of young ear in maize

$a_{1} \sim a_{5}$ 分别代表小穗分化期 $\left(6\right.$ 月 29 日)的 A1B1 A1B5; $b_{1} \sim b_{5}$ 分别代表小穗分化期 $\left(6\right.$ 月 29 日)的 A2B1 A2B5; $c_{1} \sim c_{5}$ 分别代表小花分化期 (7 月 7 日)的 $\mathrm{A} 1 \mathrm{~B} 1 \sim \mathrm{A} 1 \mathrm{~B} 5 ; \mathrm{d}_{1} \sim \mathrm{d}_{5}$ 分别代表小花分化期(7月 7 日)的 A2B1 A2B5。

$a_{1}-a_{5}$ represent A1B1-A1B5 at spikelet differentiation stage (June 29) respectively; $b_{1}-b_{5}$ represent A2B1-A2B5 at spikelet differentiation stage (June 29) respectively; $\mathrm{c}_{1}-\mathrm{c}_{5}$ represent A1B1-A1B5 at floret differentiation stage (July 7) respectively; $\mathrm{d}_{1}-\mathrm{d}_{5}$ represent A2B1-A2B5 at floret differentiation stage (July 7) respectively.
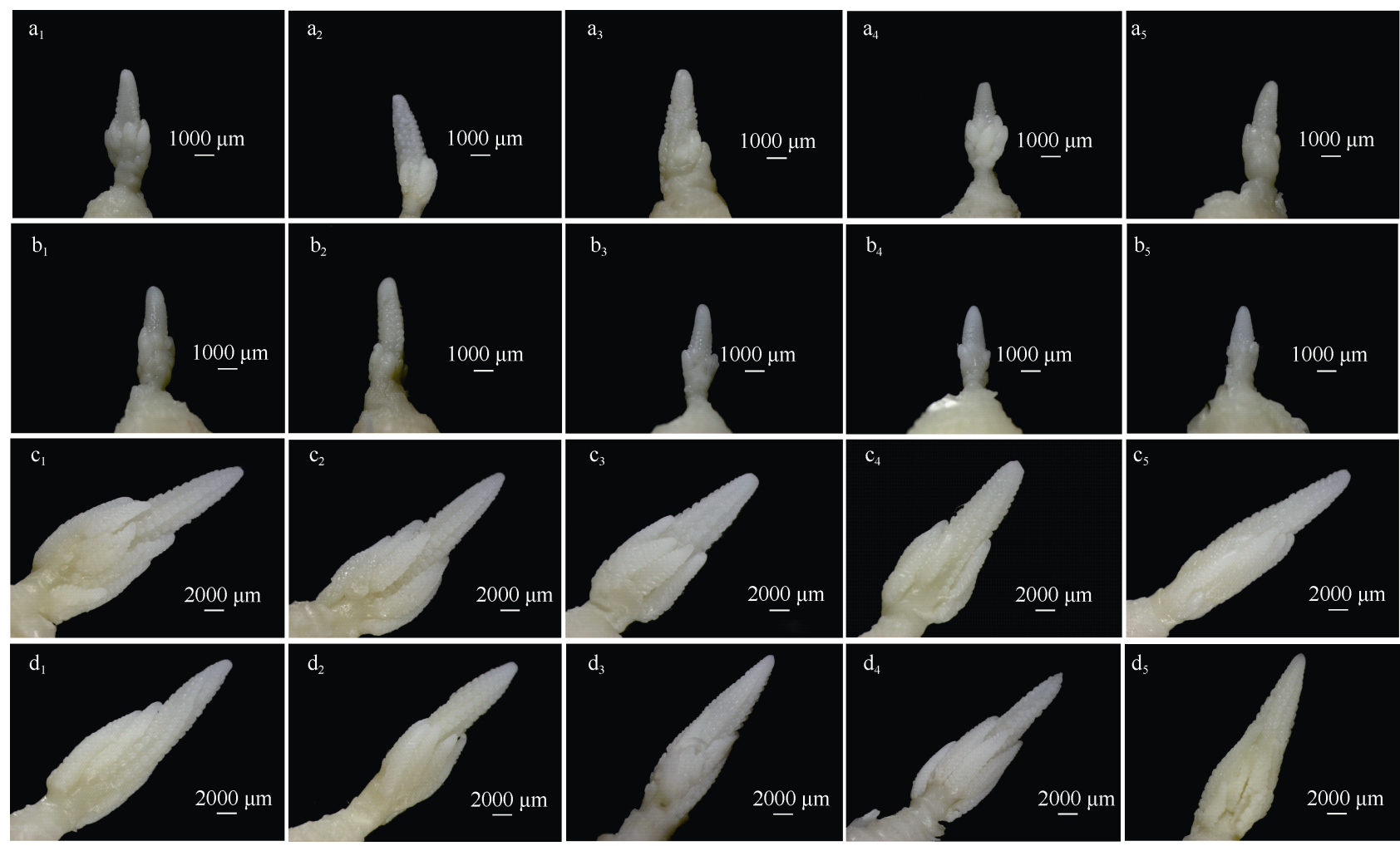

图 5 玉米雄穗小穗分化和小花分化期形态特征

Fig. 5 Morphological characteristics in spikelet differentiation and floret differentiation of young tassel in maize

$\mathrm{a}_{1} \sim \mathrm{a}_{5}$ 分别代表小穗分化期( 6 月 20 日)的 A1B1 A1B5; $b_{1} \sim \mathrm{b}_{5}$ 分别代表小穗分化期 $\left(6\right.$ 月 20 日)的 A2B1 A2B5; $\mathrm{c}_{1} \sim \mathrm{c}_{5}$ 分别代表小花分化期 (6月 26 日)的 A1B1 A1B5; $\mathrm{d}_{1} \sim \mathrm{d}_{5}$ 分别代表小花分化期( 6 月 26 日)的 A2B1 A2B5。

$\mathrm{a}_{1}-\mathrm{a}_{5}$ represent A1B1-A1B5 of the spikelet differentiation stage (June 20) respectively; $\mathrm{b}_{1}-\mathrm{b}_{5}$ represent A2B1-A2B5 at spikelet differentiation stage (June 20) respectively; $\mathrm{c}_{1}-\mathrm{c}_{5}$ represent A1B1-A1B5 at floret differentiation stage (June 26) respectively; $\mathrm{d}_{1}-\mathrm{d}_{5}$ represent A2B1-A2B5 at floret differentiation stage (June 26) respectively.

\subsection{2 对分化特性的影响 由表 3 可知, 密度和} 株行距配置对玉米雄穗主轴长度和成对小穗数有着 显著或极显著影响，密度和株行距配置互作效应对
2018 年主轴长度存在显著影响。密度增加, 两年雄 穗主轴长度和成对小穗数均降低, 其中 2017 年 A2 密度雄穗平均主轴长度和成对小穗数较 $\mathrm{A} 1$ 密度分 
别降低 $5.86 \%$ 和 $1.02 \%, 2018$ 年 $\mathrm{A} 3$ 密度较 $\mathrm{A} 1$ 密度 分别降低 $4.73 \%$ 和 $15.83 \%$, 较 $\mathrm{A} 2$ 密度分别降低 $2.22 \%$ 和 $9.01 \%$ 。 $\mathrm{A} 1$ 和 $\mathrm{A} 2$ 密度下, 平均行距增大, 雄
穗主轴长度和成对小穗数有降低趋势, 宽窄行与其 相应等行距相比, 雄穗主轴长度和成对小穗数也有 降低趋势, 但在 $\mathrm{A} 3$ 密度平均行距为 $80 \mathrm{~cm}$ 时则相反。

表 3 密度和株行距配置对玉米雄穗特性的影响

Table 3 Effects of density and row spacing on tassel characteristics of maize

\begin{tabular}{|c|c|c|c|c|c|}
\hline $\begin{array}{l}\text { 年份 } \\
\text { Year }\end{array}$ & $\begin{array}{c}\text { 密度 } \\
\text { Density }\end{array}$ & $\begin{array}{l}\text { 株行距配置 } \\
\text { Row spacing }\end{array}$ & $\begin{array}{c}\text { 主轴长度 } \\
\text { Spindle length }(\mathrm{cm})\end{array}$ & $\begin{array}{c}\text { 分枝数 } \\
\text { Branch number }\end{array}$ & $\begin{array}{c}\text { 成对小穗数 } \\
\text { Spikelet number }\end{array}$ \\
\hline \multirow[t]{15}{*}{2017} & A1 & B1 & $46.55 \mathrm{a}$ & $8.50 \mathrm{a}$ & $364.13 \mathrm{a}$ \\
\hline & & B2 & $46.25 \mathrm{a}$ & $8.25 \mathrm{a}$ & $348.00 \mathrm{ab}$ \\
\hline & & B3 & $45.90 \mathrm{a}$ & $8.75 \mathrm{a}$ & $344.00 \mathrm{~b}$ \\
\hline & & B4 & $45.45 \mathrm{ab}$ & $8.25 \mathrm{a}$ & $342.50 \mathrm{~b}$ \\
\hline & & B5 & $44.63 \mathrm{~b}$ & $8.50 \mathrm{a}$ & $336.25 \mathrm{~b}$ \\
\hline & & 平均值 Average & $45.76 \mathrm{~A}$ & $8.45 \mathrm{~A}$ & $346.98 \mathrm{~A}$ \\
\hline & A2 & B1 & $44.75 \mathrm{a}$ & $8.50 \mathrm{a}$ & $352.50 \mathrm{a}$ \\
\hline & & B2 & $43.45 \mathrm{ab}$ & $8.00 \mathrm{a}$ & $350.75 \mathrm{a}$ \\
\hline & & B3 & $43.18 \mathrm{~b}$ & $8.50 \mathrm{a}$ & $341.75 \mathrm{a}$ \\
\hline & & B4 & $42.00 \mathrm{~b}$ & $8.25 \mathrm{a}$ & $337.50 \mathrm{a}$ \\
\hline & & B5 & $42.00 \mathrm{~b}$ & $8.00 \mathrm{a}$ & $335.00 \mathrm{a}$ \\
\hline & & 平均值 Average & $43.08 \mathrm{~A}$ & $8.25 \mathrm{~A}$ & $343.50 \mathrm{~A}$ \\
\hline & $F$ 值 & 密度 Density (D) & $18.55^{*}$ & 3.00 & 2.71 \\
\hline & $F$-value & 行距 Row spacing (R) & $5.16^{* *}$ & 0.38 & $3.02^{*}$ \\
\hline & & 密度 $\times$ 行距 $\mathrm{D} \times \mathrm{R}$ & 0.52 & 0.10 & 0.27 \\
\hline \multirow[t]{18}{*}{2018} & A1 & B1 & $59.00 \mathrm{a}$ & $9.40 \mathrm{a}$ & $355.00 \mathrm{a}$ \\
\hline & & $\mathrm{B} 2$ & $58.60 \mathrm{a}$ & $8.80 \mathrm{a}$ & $326.40 \mathrm{ab}$ \\
\hline & & B3 & $57.30 \mathrm{ab}$ & $9.80 \mathrm{a}$ & $343.60 \mathrm{a}$ \\
\hline & & B4 & $56.00 \mathrm{~b}$ & $9.40 \mathrm{a}$ & $319.40 \mathrm{~b}$ \\
\hline & & 平均值 Average & $57.73 \mathrm{~A}$ & $9.35 \mathrm{~A}$ & $336.10 \mathrm{~A}$ \\
\hline & A2 & B1 & $56.70 \mathrm{ab}$ & $9.20 \mathrm{a}$ & $315.20 \mathrm{a}$ \\
\hline & & $\mathrm{B} 2$ & $58.50 \mathrm{a}$ & $8.80 \mathrm{a}$ & $314.60 \mathrm{a}$ \\
\hline & & B3 & $55.30 \mathrm{bc}$ & $9.20 \mathrm{a}$ & $312.60 \mathrm{a}$ \\
\hline & & B4 & $54.50 \mathrm{c}$ & $9.20 \mathrm{a}$ & $301.20 \mathrm{a}$ \\
\hline & & 平均值 Average & $56.25 \mathrm{~B}$ & $9.10 \mathrm{~A}$ & $310.90 \mathrm{~B}$ \\
\hline & A3 & B1 & $55.90 \mathrm{a}$ & $8.80 \mathrm{a}$ & $282.80 \mathrm{a}$ \\
\hline & & $\mathrm{B} 2$ & $55.50 \mathrm{a}$ & $8.60 \mathrm{a}$ & $270.80 \mathrm{a}$ \\
\hline & & B3 & $52.80 \mathrm{~b}$ & $9.00 \mathrm{a}$ & $289.00 \mathrm{a}$ \\
\hline & & B4 & $55.80 \mathrm{a}$ & $9.20 \mathrm{a}$ & $289.00 \mathrm{a}$ \\
\hline & & 平均值 Average & $55.00 \mathrm{~B}$ & $8.90 \mathrm{~A}$ & $282.90 \mathrm{C}$ \\
\hline & $F$ 值 & 密度 Density (D) & $21.09^{* *}$ & 0.34 & $29.29^{* *}$ \\
\hline & $F$-value & 行距 Row spacing (R) & $8.08^{* *}$ & 0.82 & 0.87 \\
\hline & & 密度 $\times$ 行距 $\mathrm{D} \times \mathrm{R}$ & $2.42^{*}$ & 0.11 & 0.55 \\
\hline
\end{tabular}

同列标以不同小写字母的值在处理间差异显著 $(P<0.05)$, 同列标以不同大写字母的值在处理间差异极显著 $(P<0.01) ;{ }^{*}$ 、 ${ }^{* *}$ 分别表示 0.05 和 0.01 水平上差异显著。处理同表 2 。

Values within the same column followed by different small letters are significantly different at the 0.05 probability level among treatments, and those by different capital letters at the 0.01 probability level. ${ }^{*}$ and ${ }^{* *}$ : significantly different at the 0.05 and 0.01 probability levels, respectively. Treatments described as in Table 2. 
由表 4 可知, 密度和株行距配置对玉米雌穗各 分化发育指标均有显著或极显著影响, 二者互作效 应对 2018 年正常受精小花数、退化小花数、败育花 数、花败育率和单株果穗受精率的影响均达极显著 水平。密度增加, 雌穗总小花数、吐丝小花数、正 常受精小花数和单株果穗受精率均降低, 退化小花 数、败育花数和小花败育率均增加, 其中 2017 年 A2 密度较 A 1 密度正常受精小花数和单株果穗受精 率分别降低 $6.89 \%$ 和 $2.45 \%$, 败育小花数和败育率分 别增加 $23.45 \%$ 和 $26.24 \% ; 2018$ 年 A3 密度正常受精 小花数和单株果穗受精率较 A1 密度分别降低 $13.80 \%$ 和 $6.09 \%$, 较 A2 密度分别降低 $6.52 \%$ 和 $1.79 \%$, 而败育小花数和败育率较 A1 密度分别增加 $31.16 \%$ 和 $40.30 \%$, 较 A2 密度分别增加 $8.70 \%$ 和 $12.74 \%$ 。 $\mathrm{A} 1$ 和 $\mathrm{A} 2$ 密度下, 平均行距增大, 退化小 花数、败育花数和花败育率总体呈增加趋势, 正常 受精小花数和单株果穗受精率总体呈降低趋势; 2018 年 A3 密度下, 平均行距增大, 正常受精小花数 增加, 小花败育率降低, 但处理间差异不显著。等行 距处理较相应宽窄行处理, A1 和 A2 密度下单株果 穗受精率均增加(2018 年 A2B3 降低), 而 A3 密度下 B4 (宽窄行)较 B3 (相应等行距)略微增加。可知, 密 度增加, 增加了小花败育率, 降低了单株果穗受精 率, 但搭配适宜株行距配置能够在一定程度上缓解 这效应。

\section{4 密度和株行距配置对玉米产量及其构成因 素的影响}

由表 5 可知, 随密度增加, 玉米穗长、穗粗、行 粒数、穗粒数和百粒重降低, 秃尖长增加, 果穗性状 变劣; 有效穗数随种植密度增加而增加, 但由于空 秆和倒伏也较大幅度增加, 导致其增幅逐渐降低, 最终有效穗数也降低, 尤其是 2018 年(降水多、光照 弱)行距较窄的 B1 和 B2 处理, 导致最终的玉米籽粒 产量随密度增加而先增后降, 以 A2 密度最高, 2017 年 $\mathrm{A} 2$ 密度较 A1 密度籽粒产量平均增加 $18.51 \%$, 2018 年 A2 密度较 A1 和 A3 密度则分别增加 $15.58 \%$ 和 $15.98 \%$ 。株行距配置对玉米产量及其构成也有一 定影响, 适宜的田间配置方式有利于改善穗部性状, 防止倒伏, 增加有效穗数而增产, 总体而言, 在 A 1 、 A2 密度下等行距产量高于宽窄行, 以 $60 \mathrm{~cm}$ 等行距 (B1)产量最高, 而 A3 密度下则以 $(110+50) \mathrm{cm}$ 宽窄 行(B4)处理产量最大, 但仍低于 A2B1 处理。

\section{5 相关性分析}

2.5.1 玉米产量与产量构成因素的关系产量与 有效穗数关系最为密切, 呈极显著正相关 $\left(r=0.70^{* *}\right.$, $n=66)$, 玉米行粒数 $\left(X_{1}\right)$ 、穗粒数 $\left(X_{2}\right)$ 和百粒重 $\left(X_{3}\right)$ 均与产量呈极显著二次函数关系。

$Y=-24136.0956+1933.0372 X_{1}-28.8069 X_{1}^{2}\left(R^{2}=0.7756^{* *}\right)$
$Y=-26200.8807+122.6164 X_{2}-0.109103 X_{2}^{2}\left(R^{2}=0.7518^{* *}\right)$
$Y=-75892.1060+6616.2220 X_{3}-130.0878 X_{3}^{2}\left(R^{2}=0.7467^{* *}\right)$

由方程可知, 玉米产量随各指标的升高而呈抛 物线变化, 行粒数、穗粒数和百粒重均不是越多越 好, 在行粒数、穗粒数和百粒重为 33.55 粒、561.9 粒、 $25.53 \mathrm{~g}$ 时产量最高, 因为穗粒数和千粒重受有 效穗数影响比较大, 二者呈极显著负相关, 有效穗 数过低时虽然穗粒数和千粒重高, 但产量不高, 有 效穗数过多致穗粒数、千粒重过低, 产量也不高。 密度增加, 显著增加了玉米有效穗数, 但过密会导 致穗粒数大幅降低而减产, 而合理密植利于缓和个 体与群体间的矛盾, 有利于单位面积有效穗数、穗 粒数和粒重的协调发展, 使三者乘积达到最大, 因 此在一定穗数基础上培育大穗, 增加单位面积的总 粒数, 扩大库容量具有重要意义。

\subsection{2 产量性状与雌雄分化特性及光分布的关系}

由表 6 可知, 小穗分化期和小花分化期雌雄穗 幼穗长度均与玉米穗长、穗粗、行粒数、穗粒数和 百粒重正相关, 而与秃尖长负相关，且均达显著或 极显著水平, 同时两时期雌雄幼穗中部直径均与玉 米穗长、行粒数、穗粒数和百粒重呈正相关, 表明 早期雌雄穗幼穗长度的分化状态与玉米穗部性状关 系更为密切。吐丝期雌穗小花总数、吐丝小花数、 受精小花数和单株果穗受精率分别与穗长、行粒数、 穗粒数和穗位层透光率呈显著或极显著正相关, 而 与秃尖长和消光系数呈显著或极显著负相关(单株 果穗受精率与消光系数相关不显著), 雌穗小花败育 率表现则相反; 雄穗成对小穗数与玉米穗长、行粒 数和穗粒数以及穗位层透光率均呈极显著正相关, 而与消光系数显著负相关, 表明随着生育时期的推 进, 植株内部竞争增大, 雌雄穗分化受光照条件影 响差异逐渐显现, 因此通过合理密植和适宜株行距 配置等措施, 适当降低消光系数, 增加穗位层透光 率, 改善田间通风透光条件, 有利于促进玉米雌雄 穗分化发育, 从而增加玉米行粒数和穗粒数, 减小 秃尖长度。 


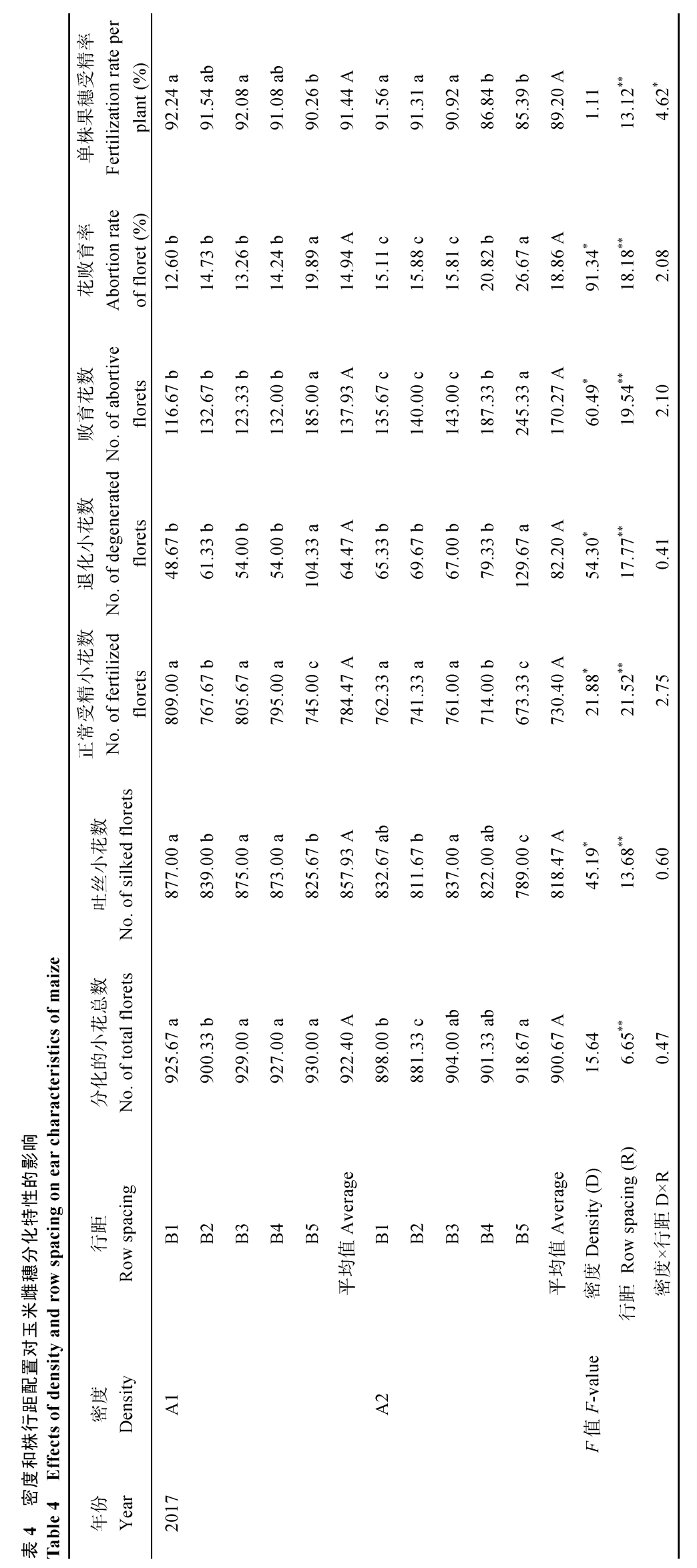




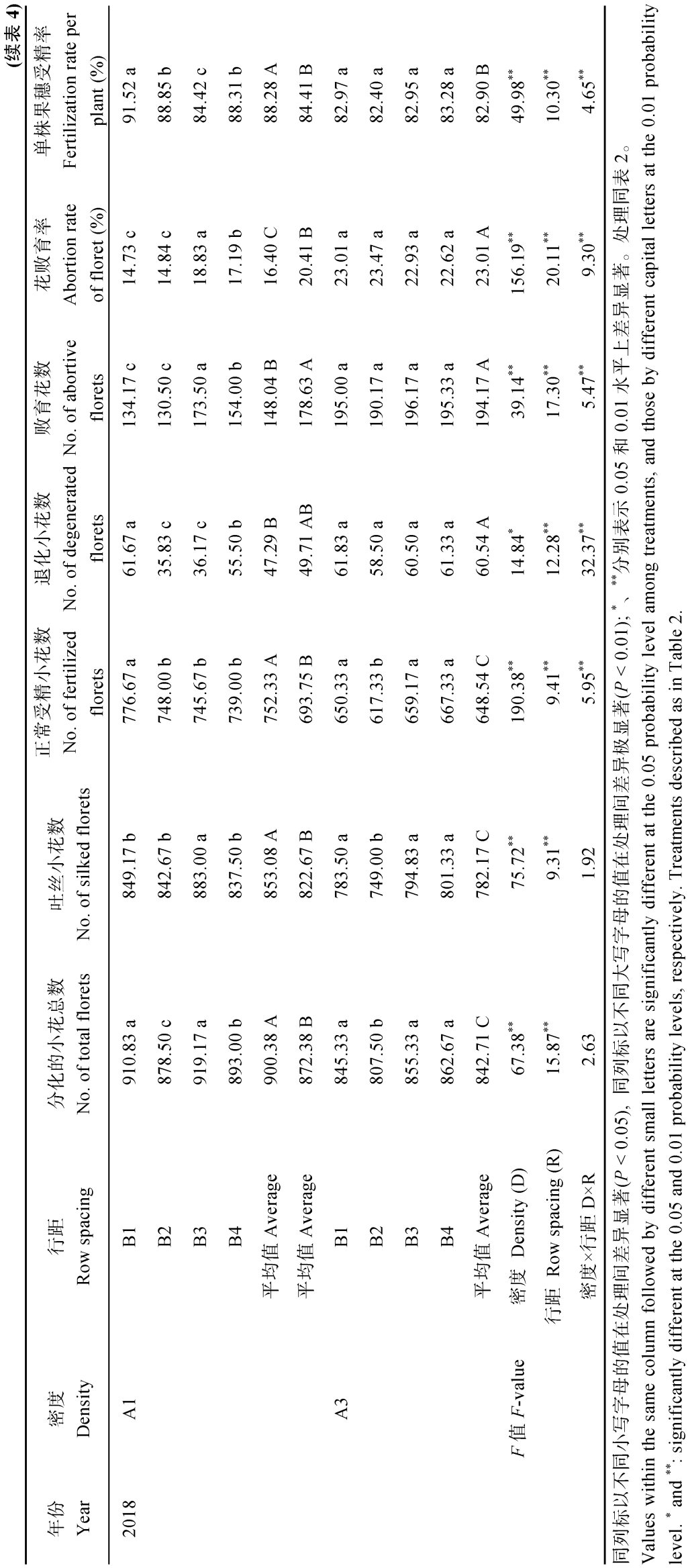




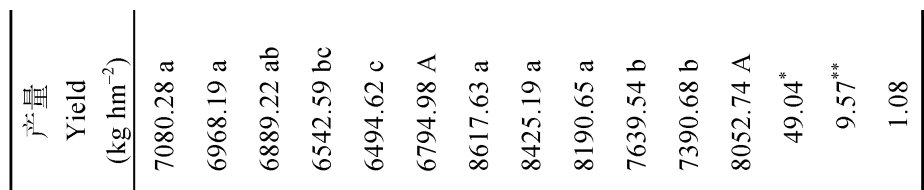

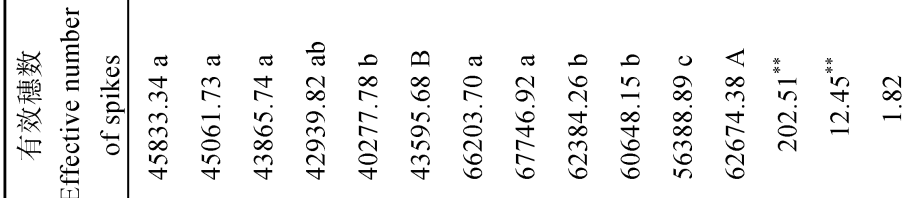

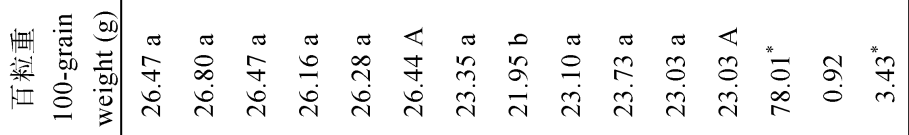

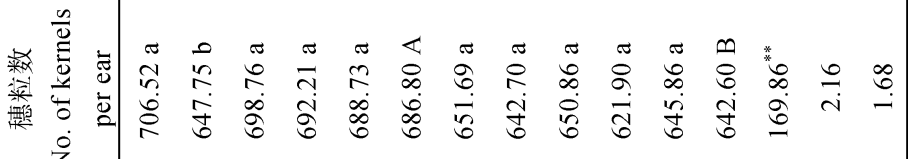

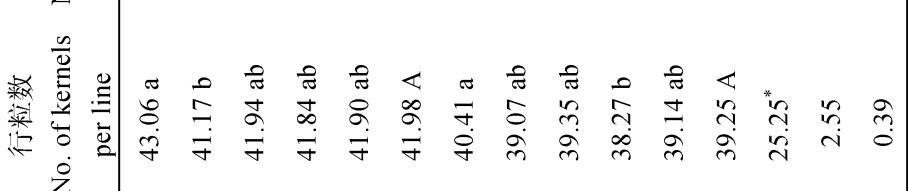

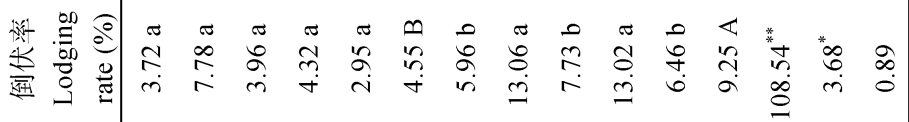

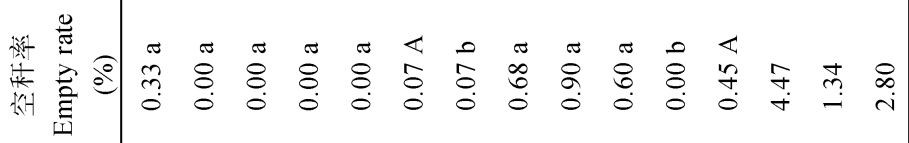

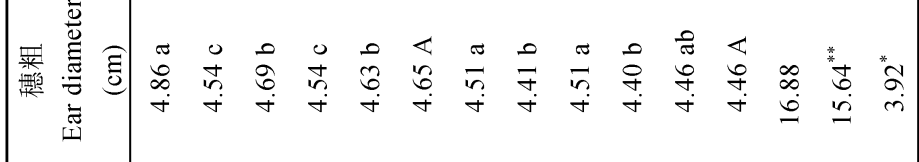

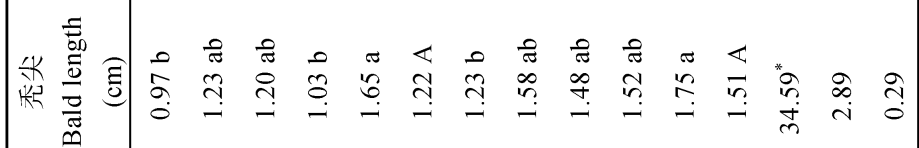

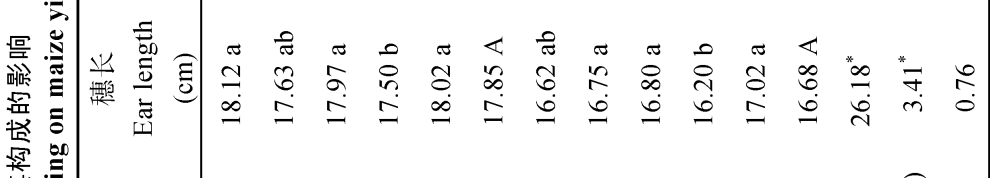

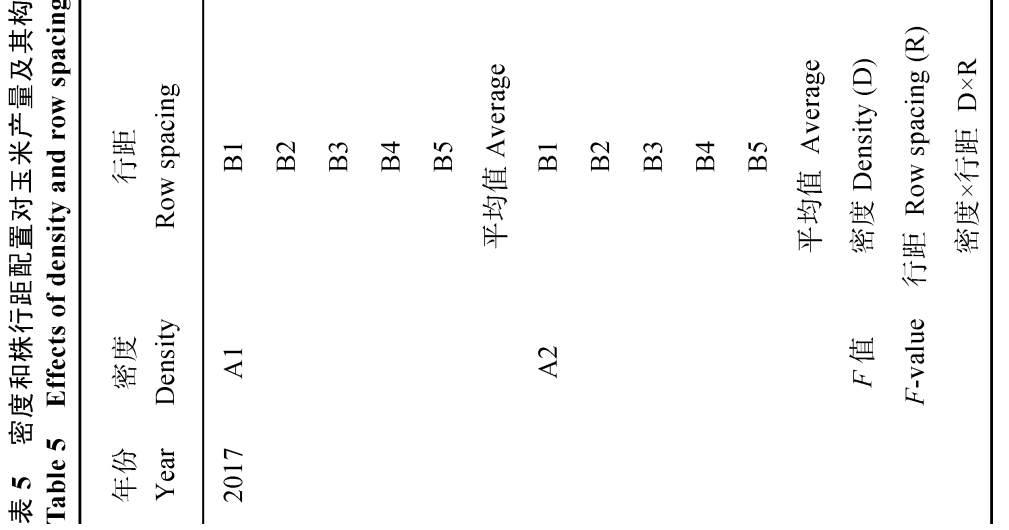




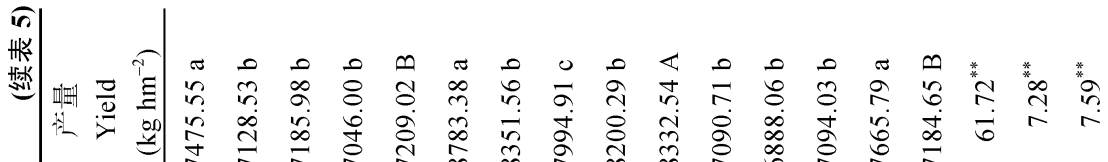

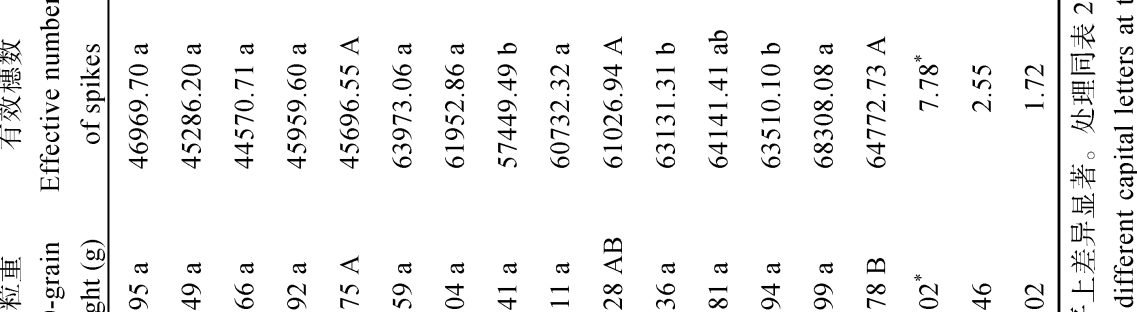

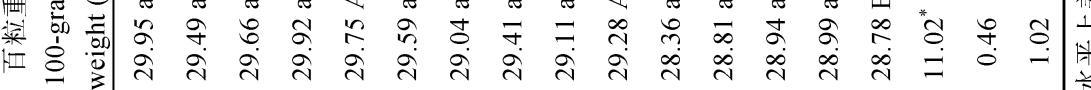

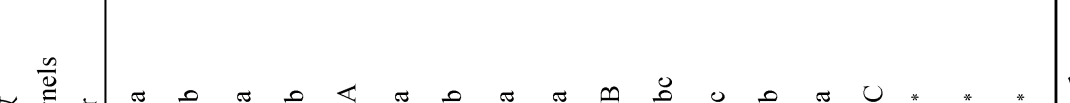
整 $\dot{z}$

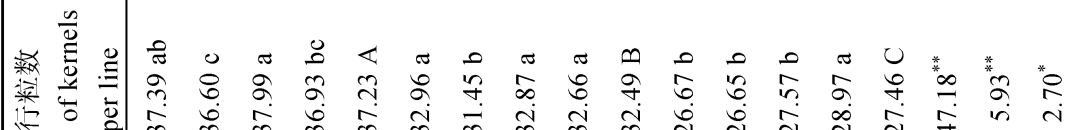
$\dot{z} \quad \mid \begin{array}{ll}0 \\ 0\end{array}$

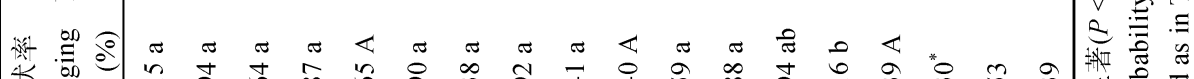

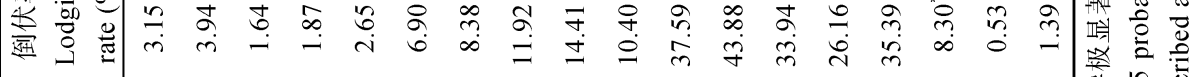

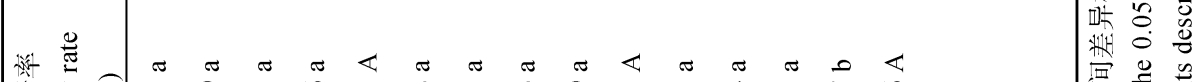

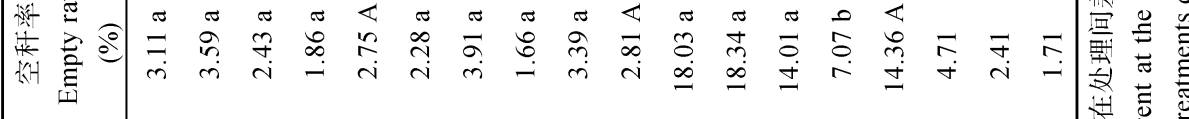
冓离离

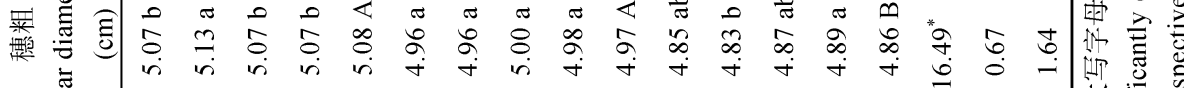

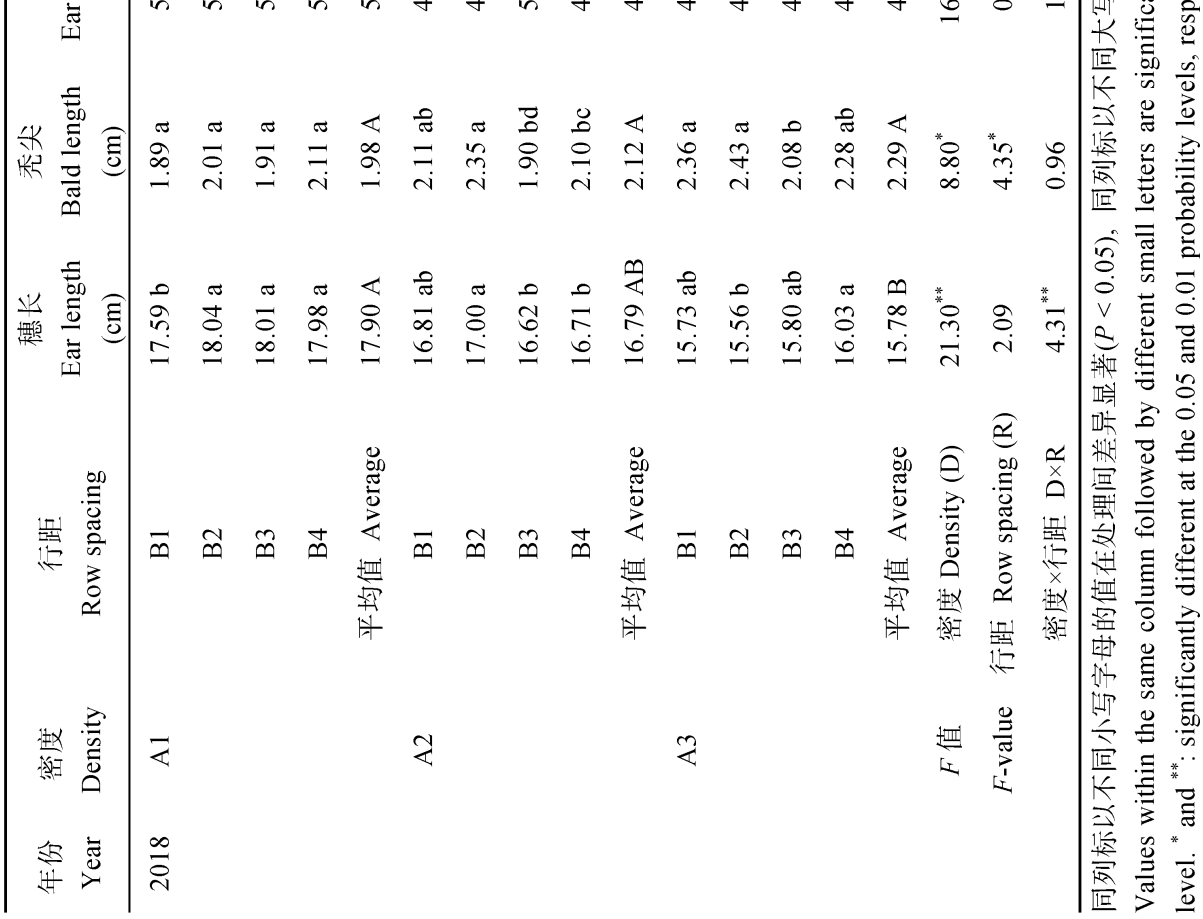




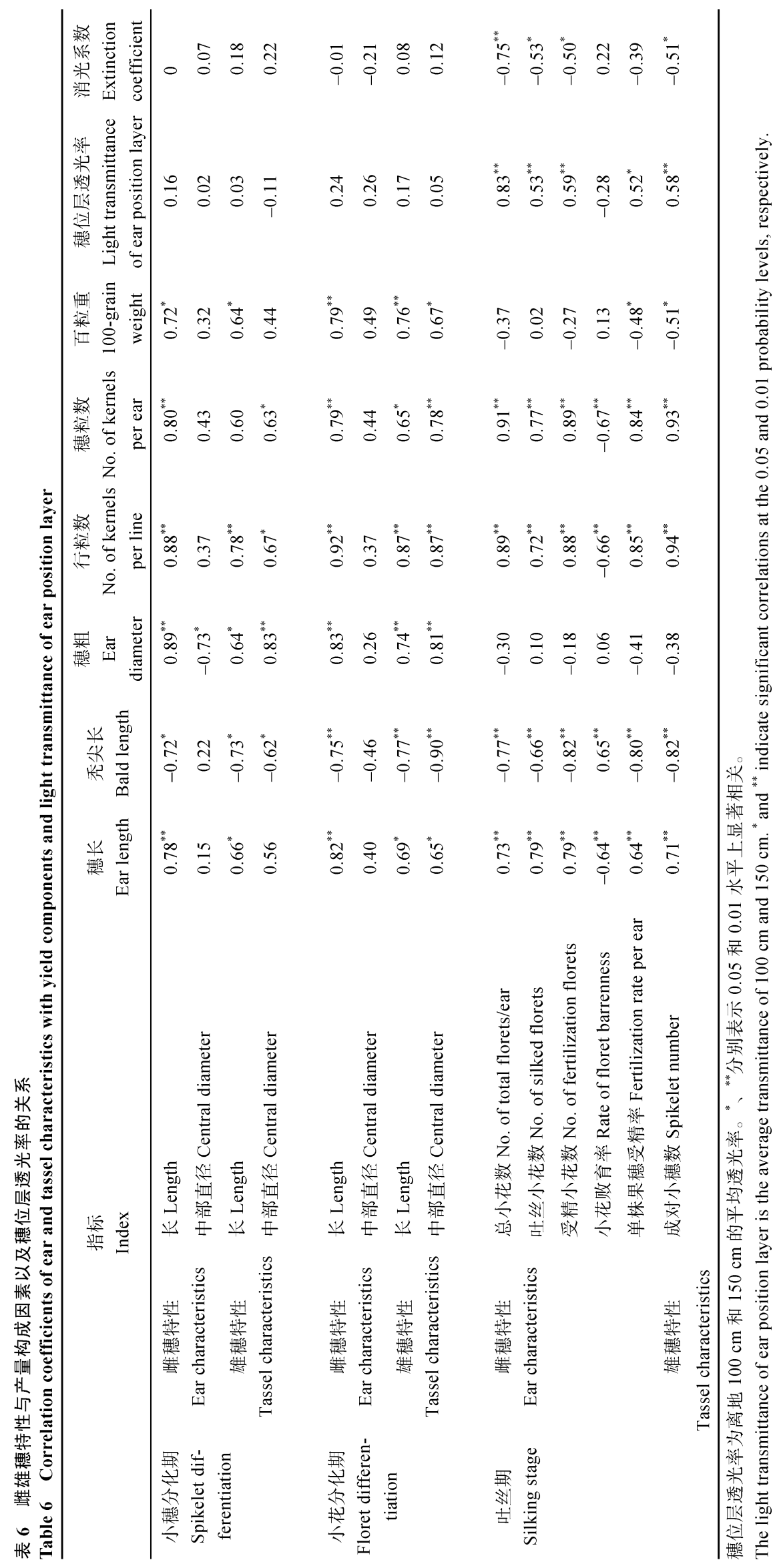


回归分析表明, 玉米的产量 $(Y)$ 与消光系数 $(K$, 宽窄行处理用其宽行和窄行的平均值)呈二次凸函 数关系, 回归方程为 $Y=850.7+1544500.4 K-$ $85979565.3 K^{2}\left(R^{2}=0.298^{*}\right)$, 在消光系数为 0.009 左 右时产量最高; 消光系数过大, 田间通风透光变差, 果穗分化发育不良, 穗粒数少, 产量不高; 消光系 数过小, 田间漏光多, 不利于增加光合物质积累, 也不利于高产。

\section{3 讨论}

合理密植可以增加有效穗数而提高玉米产量, 但种植密度过大则会影响玉米的幼穗分化, 小花总 数、吐丝小花数、受精小花数减少, 败育小花和未 受精小花数增加, 导致穗实粒数降低而减产 ${ }^{[13]}$, 本 文得到了类似结果, 本试验条件下的适宜种植密度 为 67,500 株 $\mathrm{hm}^{-2}$, 低于李春奇等 ${ }^{[13]}$ 和孟佳佳等 ${ }^{[16]}$ 在北方玉米区的研究结果, 这可能与本试验区弱光 条件有关。相关分析表明, 玉米雌穗的吐丝小花数、 受精小花数、单株果穗受精率和雄穗成对小穗数与 穗位层透光率呈显著或极显著正相关, 与其消光系 数显著负相关, 表明田间通风透光条件是影响玉米 雌雄穗分化的重要因素。玉米种植密度增加, 植株 虽然能够自动调节叶片生长角度, 使叶向值增大, 茎叶夹角和开张角变小, 从而在一定程度上改善田 间透光条件, 但其调节程度远不及密度增加对透光 率的影响, 导致群体透光率降低, 消光系数增加, 这是高密度降低玉米穗粒数的重要生态机制。密度 过大还可能因内部竞争激烈, 使植株个体发育不良, 导致空秆增加、倒伏加重而降低有效穗数, 这在多 雨、寡日的 2018 年的 90,000 株 $\mathrm{hm}^{-2}$ 超高密度下表 现尤其突出。

种植密度决定群体的大小, 而株行距配置方式 则决定群体的均匀性 ${ }^{[17-18]}$ 。改变植株在田间的分布, 可以使冠层内光分布更加均匀 ${ }^{[19]}$, 从而促进玉米雌 雄穗分化, 最终提高玉米产量及产量构成。杨吉顺 等 ${ }^{[20]}$ 在山东的研究表明, 在 67,500 株 $\mathrm{hm}^{-2}$ 密度下, $60 \mathrm{~cm}$ 等行距与各宽窄行处理 (平均行距为 $60 \mathrm{~cm}$ )的 产量差异不显著, 但在 90,000 株 $\mathrm{hm}^{-2}$ 和 112,500 株 $\mathrm{hm}^{-2}$ 密度下, $(80+40) \mathrm{cm}$ 行距处理能够增加穗位叶 层的光合有效辐射, 从而提高籽粒产量。本试验结 果表明, 在 45,000株 $\mathrm{hm}^{-2}$ 和 67,500株 $\mathrm{hm}^{-2}$ 密度下, 宽窄行 $(110+50) \mathrm{cm}$ 中宽行群体透光率增大, 存在较 多的漏光损失, $(80+40) \mathrm{cm}$ 中窄行透光率过小, 植株 间光能和养分资源竞争加剧, 不利于产量的提高,
而 $60 \mathrm{~cm}$ 等行距处理下叶型相对较紧凑, 群体内受 光较均匀, 幼穗分化发育较好, 吐丝和受精小花数 多、败育小花数和败育率低, 因而穗粒数多, 籽粒产 量最高。但在 2018 年的 90,000 株 $\mathrm{hm}^{-2}$ 超高密度下, $(110+50) \mathrm{cm}$ 宽窄行处理的宽行通风透光条件更好, 促进了雌雄穗分化发育, 进而优化玉米穗部性状, 并降低倒伏，增加有效穗而提高玉米籽粒产量。表 明在中、高密度(45,000 株 $\mathrm{hm}^{-2}$ 和 67,500 株 $\mathrm{hm}^{-2}$ ) 条件下适宜 $60 \mathrm{~cm}$ 等行距栽培, 但在超高密植 $\left(90,000\right.$ 株 $\left.\mathrm{hm}^{-2}\right)$ 条件下则应适当扩大行距, $(110+50)$ $\mathrm{cm}$ 宽窄行种植, 以改善田间通风透光条件。这一结 果与杨吉顺等 ${ }^{[20]}$ 在北方玉米区的研究结果不尽一致, 这与本区弱光条件和所用品种不同有关, 因此玉米 的株行距配置要因种植密度、当地光照等生态条件 和品种特性而异。正红 6 号是本区主推品种, 株高 适中, 株型半紧凑, 耐密性较强, 应用面积大, 具有 较高的代表性, 研究结果对指导本区域的玉米生产 有重要参考、实用价值。

消光系数反映作物群体内的光分布状态, 消光 系数高, 群体内光衰减严重, 透光条件差, 消光系 数低, 群体内透光条件好, 但可能漏光增多 ${ }^{[21]}$ 。本试 验表明, 玉米产量与消光系数呈二次凸函数关系, 消光系数过高、过低均不利于高产, 在本试验条件 下消光系数为 0.009 左右时较适宜。适宜种植密度 和株行距配置可以通过建立适宜的消光系数, 改善 田间透光条件而提高玉米产量。

\section{4 结论}

适宜密度和株行距配置能够优化株型结构, 使 群体光分布更加均匀合理, 消光系数适宜, 从而促 进玉米雌雄穗分化发育, 提高单株果穗受精率, 降 低小花败育率，优化玉米穗部性状，协调有效穗数 和穗粒数矛盾, 从而提高玉米产量。玉米产量随密 度增加而先增后降, 以 67,500 株 $\mathrm{hm}^{-2}$ 产量较高; 在 45,000 株 $\mathrm{hm}^{-2}$ 和 67,500 株 $\mathrm{hm}^{-2}$ 密度下以 $60 \mathrm{~cm}$ 等 行距、在 90,000 株 $\mathrm{hm}^{-2}$ 密度下以 $(110+50) \mathrm{cm}$ 宽窄 行产量较高。建议川中丘区采用 67,500 株 $\mathrm{hm}^{-2}$ 密 度搭配 $(60+60) \mathrm{cm}$ 等行距栽培, 不仅产量高, 而且 也比较适合大多数收获机对行收获。

\section{References}

[1] 王楷, 王克如, 王永宏, 赵健, 赵如浪, 王喜梅, 李健, 梁明晰, 李少昆. 密度对玉米产量 $\left(>15000 \mathrm{~kg} \mathrm{hm}^{-2}\right)$ 及其产量构成因子 的影响. 中国农业科学, 2012, 45: 3437-3445.

Wang K, Wang K R, Wang Y H, Zhao J, Zhao R L, Wang X M, 
Li J, Liang M X, Li S K. Effects of density on maize yield and yield components. Sci Agric Sin, 2012, 45: 3437-3445 (in Chinese with English abstract).

[2] 吕丽华, 陶洪斌, 夏来坤, 张雅杰, 赵明, 赵久然, 王璞. 不同 种植密度下的夏玉米冠层结构及光合特性. 作物学报, 2008, 34: 447-455.

Lyu L H, Tao H B, Xia L K, Zhang Y J, Zhao M, Zhao J R, Wang P. Canopy structure and photosynthesis traits of summer maize under different planting densities. Acta Agron Sin, 2008, 34: 447-455 (in Chinese with English abstract).

[3] 冀华, 李宏, 张树伟. 玉米雌雄穗发育及其与产量的关系. 山 西农业科学, 2011, 39: 754-755.

Ji H, Li H, Zhang S W. Differentiation and growth of the male and female ears and the relationship with yield in maize. $J$ Shanxi Agric Sci, 2011, 39: 754-755 (in Chinese with English abstract).

[4] 高英波, 陶洪斌, 黄收兵, 田北京, 王丽君, 李芸, 任建宏, 王 璞. 密植和行距配置对夏玉米群体光分布及光合特性的影响. 中国农业大学学报, 2015, 20(6): 9-15.

Gao Y B, Tao H B, Huang S B, Tian B J, Wang L J, Li Y, Ren J H, Wang P. Effects of high planting density and row spacing on canopy light distribution and photosynthetic characteristics of summer maize. J China Agric Univ, 2015, 20(6): 9-15 (in Chinese with English abstract).

[5] 茬建峰, 张海红, 李鸿萍, 董朋飞, 李潮海. 不同行距配置方 式对夏玉米冠层结构和群体抗性的影响. 作物学报, 2016, 42: 104-112.

Chang J F, Zhang H H, Li H P, Dong P F, Li C H. Effects of different row spaces on canopy structure and resistance of summer maize. Acta Agron Sin, 2016, 42: 104-112 (in Chinese with English abstract).

[6] 韩成卫, 孔晓民, 刘丽, 曾苏明. 不同种植模式对玉米生长发 育、产量及机械化收获效率的影响. 玉米科学, 2012, 20(6): 89-93.

Han C W, Kong X M, Liu L, Zeng S M. Contrast test for maize different planting patterns under the mechanize harvest. $J$ Maize Sci, 2012, 20(6): 89-93 (in Chinese with English abstract).

[7] 梁秀兰, 张振宏. 玉米穗分化与叶龄关系的研究. 华南农业大 学学报, 1995, (3): 83-87.

Liang X L, Zhang Z H. Study on the relationship between ear differentiation and leaf age in maize. $J$ South China Agric Univ, 1995, (3): 83-87 (in Chinese).

[8] 李叶蓓, 陶洪斌, 王若男, 张萍, 吴春江, 雷鸣, 张巽, 王璞. 干旱对玉米穗发育及产量的影响. 中国生态农业学报, 2015, 23: 383-391.

Li Y B, Tao H B, Wang R N, Zhang P, Wu C J, Lei M, Zhang X, Wang P. Effect of drought on ear development and yield of maize. Chin J Eco-Agric, 2015, 23: 383-391 (in Chinese with English abstract).

[9] 滕世云. 玉米穗分化与叶龄的关系. 山西农业科学, 1983, (4): 4-5.

Teng S Y. Relationship between ear differentiation and leaf age. $J$ Shanxi Agric Sci, 1983, (4): 4-5 (in Chinese).

[10] 曹彬, 张世杰, 孙占育, 曹三潮, 赵志红. 玉米叶龄指数与穗 分化回归关系的研究初报. 玉米科学, 2005, 13(1): 86-88.

Cao B, Zhang S J, Sun Z Y, Cao S C, Zhao Z H. Research report of regression relationship between leaf number index and spike differentiation in maize. J Maize Sci, 2005, 13(1): 86-88 (in Chinese with English abstract).

[11] 张养利, 李进仓, 张德仓. 16 个玉米新品种叶龄指数与穗分化
关系的试验初报. 陕西农业科学, 2009, 55(5): 14-16.

Zhang Y L, Li J C, Zhang D C. Preliminary report on the relationship between leaf age index and ear differentiation of 16 new maize varieties. Shaanxi J Agric Sci, 2009, 55(5): 14-16 (in Chinese).

[12] 黄铨, 罗守德, 武殿林, 郭国光, 王先娥. 玉米穗分化时期与 植株外部形态及叶龄指数相互关系的研究. 山西农业科学, 1981, (10): 6-8.

Huang Q, Luo S D, Wu D L, Guo G G, Wang X E. Study on the relationship between the ear differentiation stage of maize and the external morphology and leaf age index of plants. Shanxi J Agric Sci, 1981, (10): 6-8 (in Chinese).

[13] 李春奇, 郑慧敏, 李芸, 李潮海. 种植密度对夏玉米雌穗发育 和产量的影响. 中国农业科学, 2010, 43: 2435-2442.

Li C Q, Zheng H M, Li Y, Li C H. Effect of planting density on the yield and development of maize ear. Sci Agric Sin, 2010, 43: 2435-2442 (in Chinese with English abstract).

[14] 徐正进, 董克. 水稻叶片基角、开张角和披垂度的同时测定方 法. 沈阳农业大学学报, 1991, 22(2): 185-187.

$\mathrm{Xu}$ Z J, Dong K. Simultaneous determination method of base angle, opening angle and sag of rice leaves. J Shenyang Agric Univ, 1991, 22(2): 185-187 (in Chinese).

[15] Wang Q, Niu Y. Effects of altered source-sink ratio on canopy, photosynthetic rate and yield of maize (Zea mays L.). Photosynthetica, 1996, 32: 271-276.

[16] 孟佳佳, 董树亭, 石德杨, 张海燕. 玉米雌穗分化与籽粒发育 及败育的关系. 作物学报, 2013, 39: 912-918.

Meng J J, Dong S T, Shi D Y, Zhang H Y. Relationship of ear differentiation with kernel development and barrenness in maize (Zea mays L.). Acta Agron Sin, 2013, 39: 912-918 (in Chinese with English abstract).

[17] Mohammadi G R, Ghobadi M E, Sheikhehpoor S. Phosphate biofertilizer, row spacing and plant density effects on corn yield and weed growth. Am J Plant Sci, 2012, 3: 425-429.

[18] 代旭峰, 王国强, 刘志斋, 王久光, 马宇, 蔡一林. 不同密度 下不同行距对玉米光合及产量的影响. 西南大学学报(自然科 学版), 2013, 35(3): 15-21.

Dai X F, Wang G Q, Liu Z Z, Wang J G, Ma Y, Cai Y L. Effects of different row spacing on photosynthesis and yield of maize under different densities. J Southwest Univ (Nat Sci Edn), 2013, 35(3): 15-21 (in Chinese with English abstract).

[19] Maddonni G A, Chelle M, Drouet J L, Andrieu B. Light interception of contrasting azimuth canopies under square and rectangular plant spatial distributions: simulations and crop measurements. Field Crops Res, 2001, 70: 1-13.

[20] 杨吉顺, 高辉远, 刘鹏, 李耕, 董树亭, 张吉旺, 王敬锋. 种植 密度和行距配置对超高产夏玉米群体光合特性的影响. 作物 学报, 2010, 36: 1226-1233.

Yang J S, Gao H Y, Liu P, Li G, Dong S T, Zhang J W, Wang J F. Effects of planting density and row spacing on canopy apparent photosynthesis of high-yield summer corn. Acta Agron Sin, 2010, 36: 1226-1233 (in Chinese with English abstract).

[21] 刘朝巍, 张恩和, 谢瑞芝, 刘武仁, 李少昆. 不同施氮方式 对宽窄行交替休闲种植玉米产量和光合特性的影响. 草业 学报, 2012, 21(1): 34-42.

Liu C W, Zhang E H, Xie R Z, Liu W R, Li S K. Effect of different nitrogen methods on yield and photosynthesis of maize under the alternative fallow high stubble about narrow row and wide row. Acta Pratac Sin, 2012, 21(1): 34-42 (in Chinese with English abstract). 